NBSIR 84-2879

\title{
The NBS Tri-Directional Test Facility
}

U.S. DEPARTMENT OF COMMERCE

National Bureau of Standards National Engineering Laboratory Center for Building Technology Washington, DC 20234

May 1984

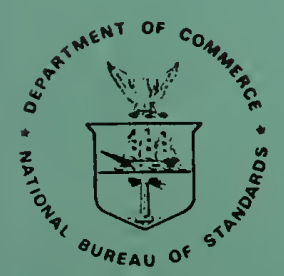

U.S. DEPARTMENT OF COMMERCE IIONAL BUREAU OF STANDARDS

$Q C$
100
.456
$34-2879$
1984



NBSIR 84-2879

THE NBS TRI-DIRECTIONAL TEST

FACILITY

Kyle Woodward

Frank Rankin

U.S. DEPARTMENT OF COMMERCE

National Bureau of Standards

National Engineering Laboratory

Center for Building Technology

Washington, DC 20234

May 1984

U.S. DEPARTMENT OF COMMERCE, Malcolm Baldrige, Secretary NATIONAL BUREAU OF STANDARDS, Emest Ambler. Diroctor 



\begin{abstract}
A general description of a unique structural testing apparatus is presented. The apparatus is called the NBS Tri-directional Test Facility (NBS/TTF). The NBS/TTF can subject large structural elements to a wide variety of threedimensional loadings including both translations and rotations in three orthogonal directions. The facility is computer based with all aspects of data acquisition, reduction, and display coordinated and controlled by a minicomputer. The minicomputer also controls the loading of test specimens as directed by the operator. The loads are applied by a closed-loop hydraulic system having seven independently servo-controlled hydraulic actuators. Test specimens having dimensions as large as $3 \mathrm{~m}$ long by $3 \mathrm{~m}$ deep by $3.5 \mathrm{~m}$ high may be installed and tested in the facility. Lateral forces of up to $+900 \mathrm{kN}$ may be imposed on the test specimen in combination with vertical forces of up to $\pm 1800 \mathrm{kN}$.
\end{abstract}


ABSTRACT . . . . . . . . . . . . . . . . . . . . $i$

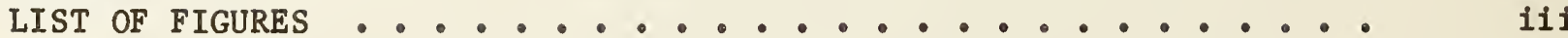

1. INTRODUCTION . . . . . . . . . . . . . . . 1

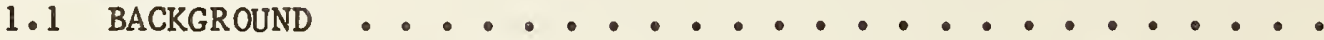

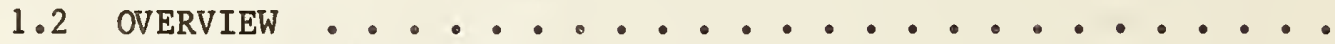

1.3 GENERAL CAPABILITIES ................. .

$1.4 \mathrm{NBS} / \mathrm{TTF}$ COMPONENTS...............

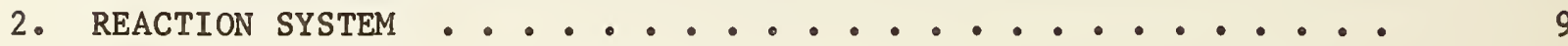

3. LOADING SYSTEM . . . . . . . . . . . . . . . . 13

4. LOAD DISTRIBUTION SYSTEM AND ACTUATOR POSITIONING BEAMS • • • 15

5. CONTROL SYSTEM HARDWARE . . . . . . . . . . . . . 17

5.1 MINICOMPUTER AND PERIPHERALS • • • . . . . . . . . . 17

5.2 ANALOG-TO-DIGITAL CONVERTER (ADC) . . . . . . . . . 17

5.3 DIGITAL-TO-ANALOG CONVERTER (DAC) . . . . . . . . . 18

5.4 SERVO-CONTROLLER . . . . . . . . . . . . . . . . 18

6. CONTROL SYSTEM SOFTWARE . . . . . . . . . . . . . 19

6.1 ORGANIZATI ON . . . . . . . . . . . . . . . . . . . . 19

6.2 DATA ACQUISITION AND STORAGE ............ 19

6.3 HYDRAULIC ACTUATOR CONTROL . . . . . . . . . . . . . . . . . 20

6.4 DATA DISPLAY . . . . . . . . . . . . . . . . . . . . . 20

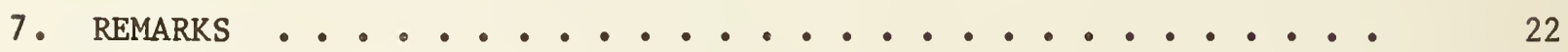

8. ACKNOWLEDGEMENT . . . . . . . . . . . . . . . . . . 23

APPENDIX A: A PICTORIAL DESCRIPTION OF THE CONSTRUCTION OF THE

NBS / TTF . . . . . . . . . . . . . . . . 


\section{LIST OF FIGURES}

Figure 1.1. Crosshead-test specimen arrangement . . . . . . . . .

Figure 1.2. Simplified sketch of NBS/TTF . . . . . . . . . . • •

Figure 1.3. NBS/TTF . . . . . . . . . . . . . . . . . . 6

Figure 1.4. Hydraulic actuator arrangement . . . . . . . . • . . 7

Figure 1.5. Control system schematic . . . . . . . . . . . . . 8

Figure 2.1. Components of reaction system . . . . . . . . . . .

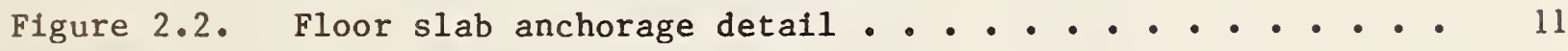

Figure 2.3. Buttress detail . . . . . . . . . . . . . . . . 12

Figure 3.1. Hydraulic actuator components . • • • • • . . . . . 14

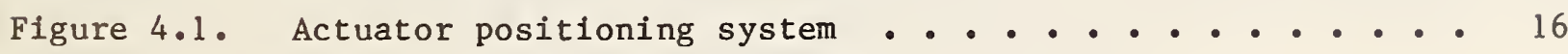

Figure A.1. Laboratory prior to construction . • • • • . • . . . 25

Figure A.2. Drilling holes in tie-down floor for rock anchors . • . 26

Figure A.3. Proof-testing an installed rock anchor . • . . . . . .

Figure A.4. Rock anchor after removal from tie-down floor . . . . . 28

Figure A.5. Roughened outline of buttress cross-section . . . . . . . 29

Figure A.6. Arrival of steel crossheads . . . . . . . . . . . . . . 30

Figure A.7. Fabrication of buttress flange reinforcment . . . . . . 31

Figure A.8. Erection of buttress flange $\quad$ - . . . . . . . . . . . . 32

Figure A.9. Buttress reinforcement in place • • • • . . . . . . . 33

Figure A.10. Pumping of buttress concrete . . . . . . . . . . . . . 34

Figure A.11. Placement of buttress concrete . . . . . . . . . . . . . 35

Figure A.12. Removal of buttress forms . . . . . . . . . . . . . . 36

Figure A.13. Installation of lower crosshead . . . . . . . . . . . . 37

Figure A.14. NBS/TTF nearing completion . . . . . . . . . . . . . . 38 



\section{INTRODUCTION}

In support of the National Bureau of Standards' (NBS) legislated mission to assist in the development of improved design procedures for buildings subject to earthquakes, the NBS Center for Building Technology has constructed a unique structural testing apparatus. The apparatus, referred to as the NBS Tridirectional Test Facility (NBS/TTF), is capable of applying controlled displacements and/or forces in three orthogonal directions simultaneously.

\section{BACKGROUND}

Structures which are subjected to seismic disturbances undergo displacements which include components in three orthogonal directions. As a result, the structural elements which make up the load resisting framework of the structure are also subjected to three-dimensional actions, including both translations and rotations in all three orthogonal directions. However, much of the research on structural component behavior, including ultimate resistances, has been done using two-dimensional representations of the actual imposed conditions. (Such representations generally impose translations and rotations in only two orthogonal directions.) It is necessary to validate the results from such simplified test procedures with data obtained from tests which better represent the threedimensional nature of the seismic response of structures.

One currently used testing technique is the shake table test. A shake table is a platform on which test specimens are constructed and then vibrated using a movement pattern modeled from some previously recorded seismic event. While shake table tests include dynamic effects (inertial effects and damping) they rarely, if ever, include motions which incorporate translations and rotations in three orthogonal directions.

Another technique currently used in structural testing is the "quasi-static" test. Here, loads are imposed on the test specimen slowly, thereby eliminating dynamic effects. However, a compensating advantage is the ability to closely observe test specimen behavior during the test. The elimination of the dynamic requirements simplifies the application of forces in all three dimensions. For these reasons, the "quasi-static" approach was selected by the NBS researchers as the basis for the development of the NBS/TTF.

\subsection{OVERVIEW}

The general concept of the NBS/TTF is straightforward, but its actual implementation is complex. At its most basic level the NBS/TTF is an apparatus which controls the actions of two opposite ends of a test specimen. The test specimen $1 \mathrm{~s}$ placed between and attached to a pair of loading surfaces (crossheads) as shown in simplified form in figure 1.1. The lower crosshead is attached to a structural tie-down floor and is stationary. The upper crosshead is maintained in position by seven hydraulic actuators. Lateral (horizontal) forces are resisted by vertical buttresses and vertical forces by the tie-down floor. A simplifled 
depiction of the arrangement is shown in figure 1.2 and the actual NBS/TTF is presented in figure 1.3 .

The loading apparatus of the NBS/TTF is composed of a moving (upper) crosshead and a stationary (lower) crosshead. The actions of the seven hydraulic actuators (figure 1.4) directly control all six degrees of freedom (dof) of the upper crosshead. The six dof consist of translations vertically and along each crosshead arm and rotations about each of the translational axes. The upper crosshead can impose any combination of values for the six dof on a test specimen, within the limits of the hydraulic actuator capacities (see section 1.3).

A schematic of the equipment associated with the control system is shown in figure 1.5. The schematic illustrates the primary information necessary to the operation of the control system. The control system equipment is interfaced with the operator by means of computer programs (software) which coordinate the activities of the facility hardware to accomplish the user specified objectives. The NBS/TTF is completely computer based permitting complex tasks to be directed by simple instructions and, thereby, greatly improving the overall efficiency of a test program. The data acquired during a test are stored by the computer for future use. Much of the data reduction and display can be done automatically with little direct operator intervention. The philosophy of the software is to minimize direct user interaction with the NBS/TTF hardware during its operation. The software commands are tallored for convenient use and generally make use of English word commands and worksheet display entry.

\subsection{GENERAL CAPABILITIES}

The NBS/TTF is contained in a three-story open bay room serviced by two overhead bridge cranes each having a capacity of $90 \mathrm{kN}$. The room is environmentally controlled, but has direct outside access through an overhead garage-type door, $5 \mathrm{~m}$ wide and $4 \mathrm{~m} \mathrm{high.} \mathrm{Normal} \mathrm{laboratory} \mathrm{facilities} \mathrm{are} \mathrm{available} \mathrm{includ-}$ ing compressed air to $850 \mathrm{kPa}$, hot, cold, and chilled water, and low- and high-pressure steam.

The NBS/TTF can accomodate test specimens which have dimensions less than $3 \mathrm{~m}$ long by $3 \mathrm{~m}$ deep by $3.5 \mathrm{~m}$ high. The vertical height of a test specimen includes any attachments necessary to connect the specimen to the crossheads.

The force and displacement limits are not readily defined since actual test conditions have a significant effect. As a guide, however, the displacement in each of the three translational directions is limited to $+50 \mathrm{~mm}$. The force 1 imits are $\pm 1800 \mathrm{kN}$ vertical, $\pm 900 \mathrm{kN}$ in one lateral direction, and $\pm 700 \mathrm{kN}$ in the other lateral direction.

The rate of displacement change is slow (less than $20 \mathrm{~mm}$ per second) since the NBS/TTF is designed to test specimens slowly, but with well-defined applied actions. The NBS/TTF as currently configured is not intended for use where fast loading rates or a large number of loading repetitions is required. 


\subsection{NBS/TTF COMPONENTS}

For purposes of discussion, the NBS/TTF is divided into five major systems. They include: the reaction system, the loading system, the load distribution system, the control system hardware, and the control system software. The remainder of this report is organized on the basis of these systems. A pictorial description of the construction of the NBS/TTF is presented in an appendix. The purpose of this report is to provide a general description of the NBS/TTF. The discussion is devoted to an understanding of the concept, capabilities, and sophistication of the NBS/TTF. 


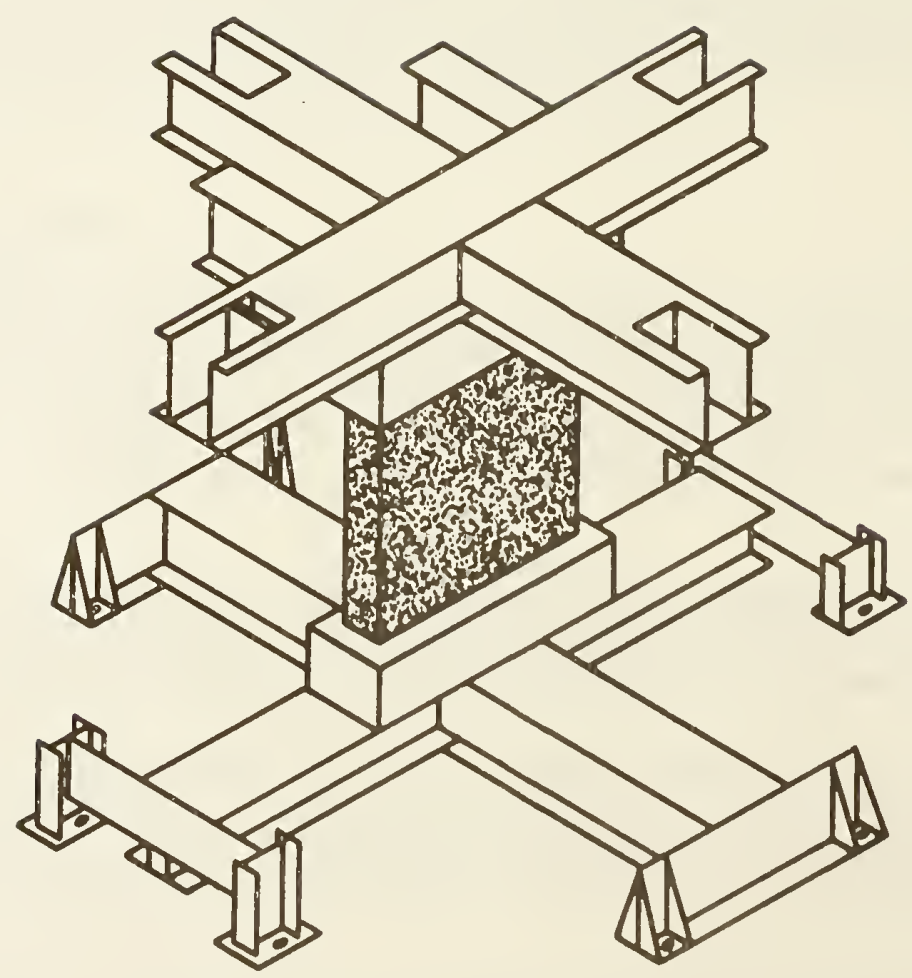

Figure 1.1. Crosshead-test specimen arrangement 


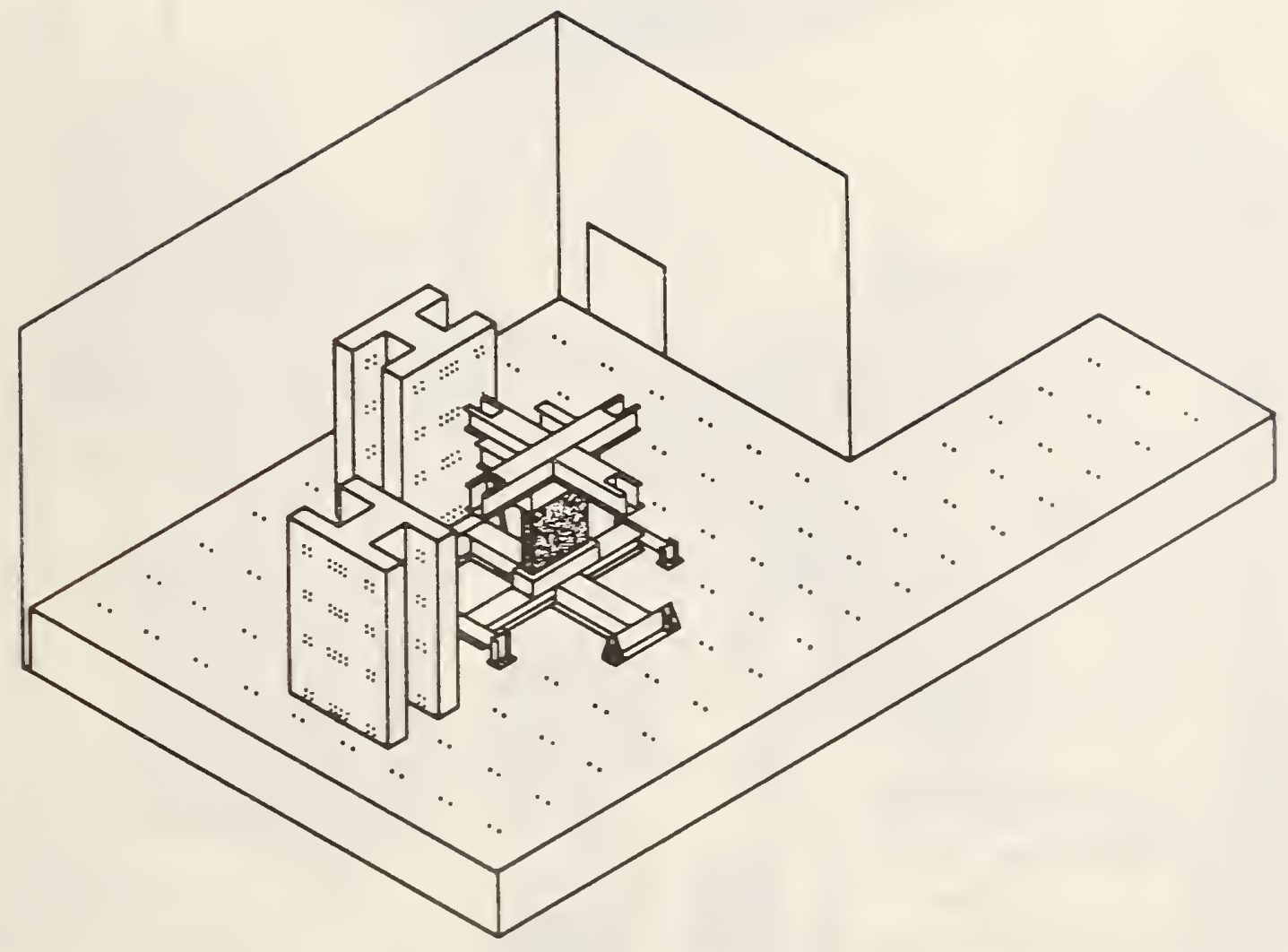

Figure 1.2. Simplified sketch of NBS/TFF 


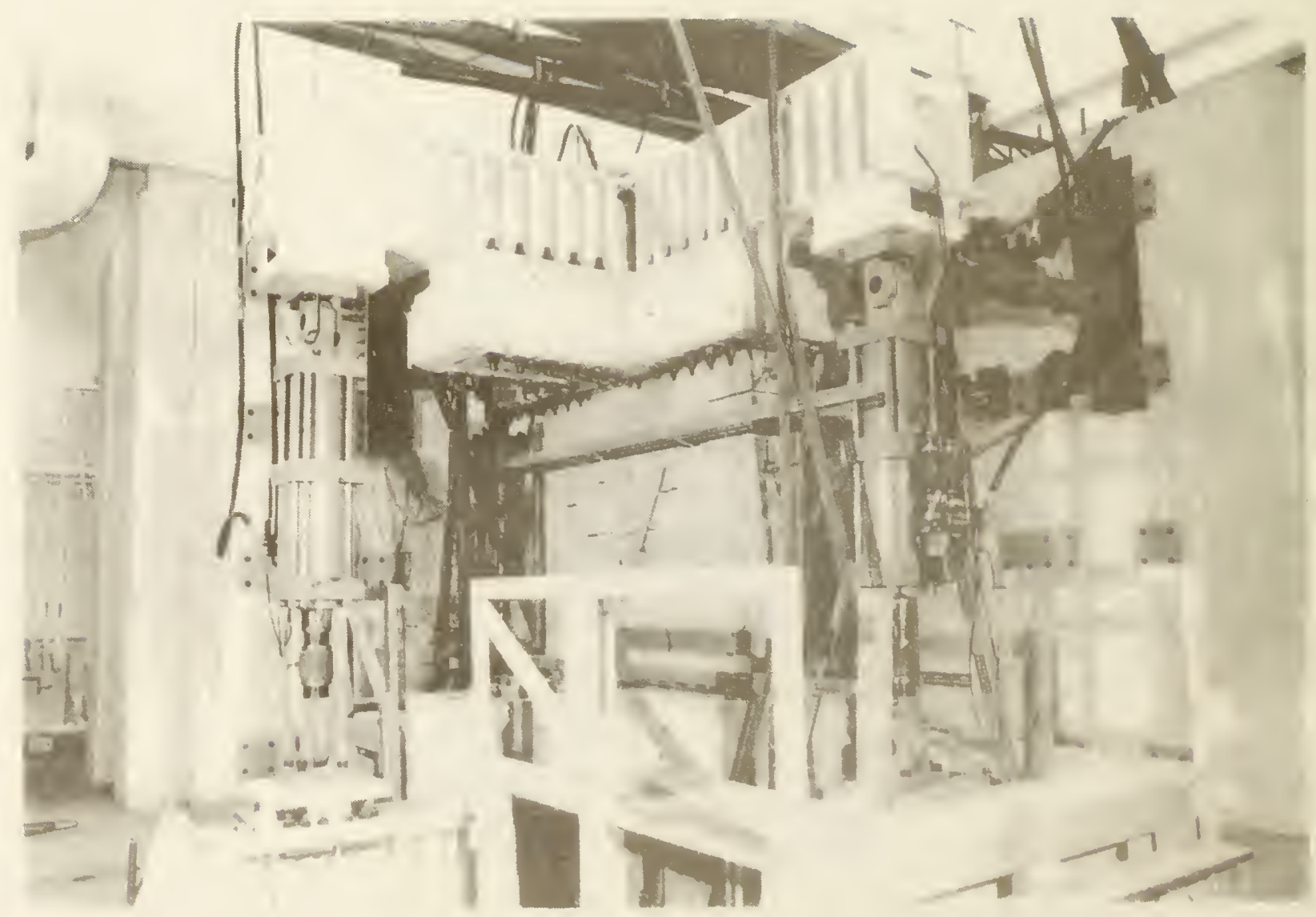

Figure 1.3. NBS/TTF 


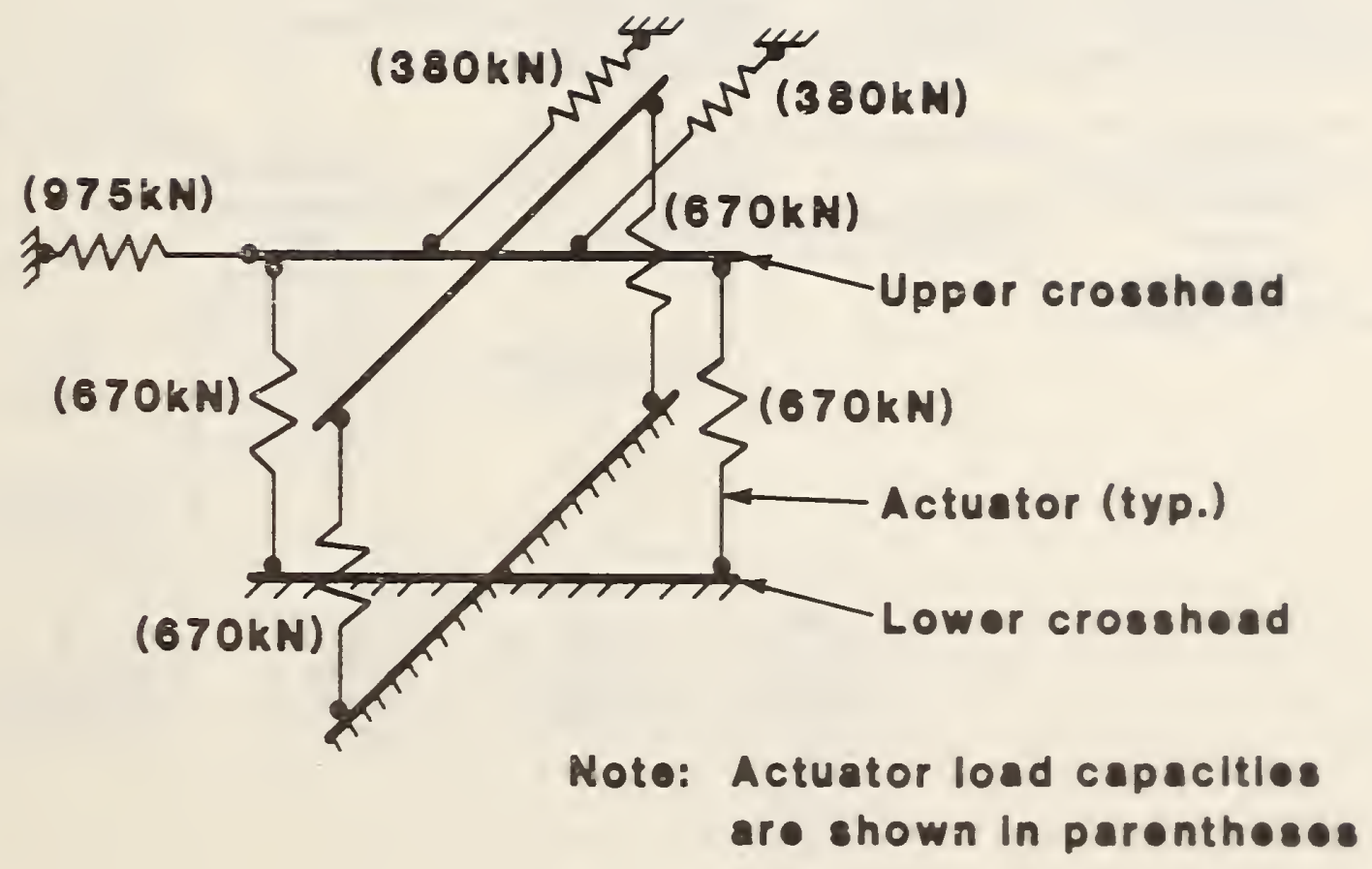

Figure 1.4. Hydraulic actuator arrangement 
NBS/TTF CONTAOL SYSTEM SCHEMATIC

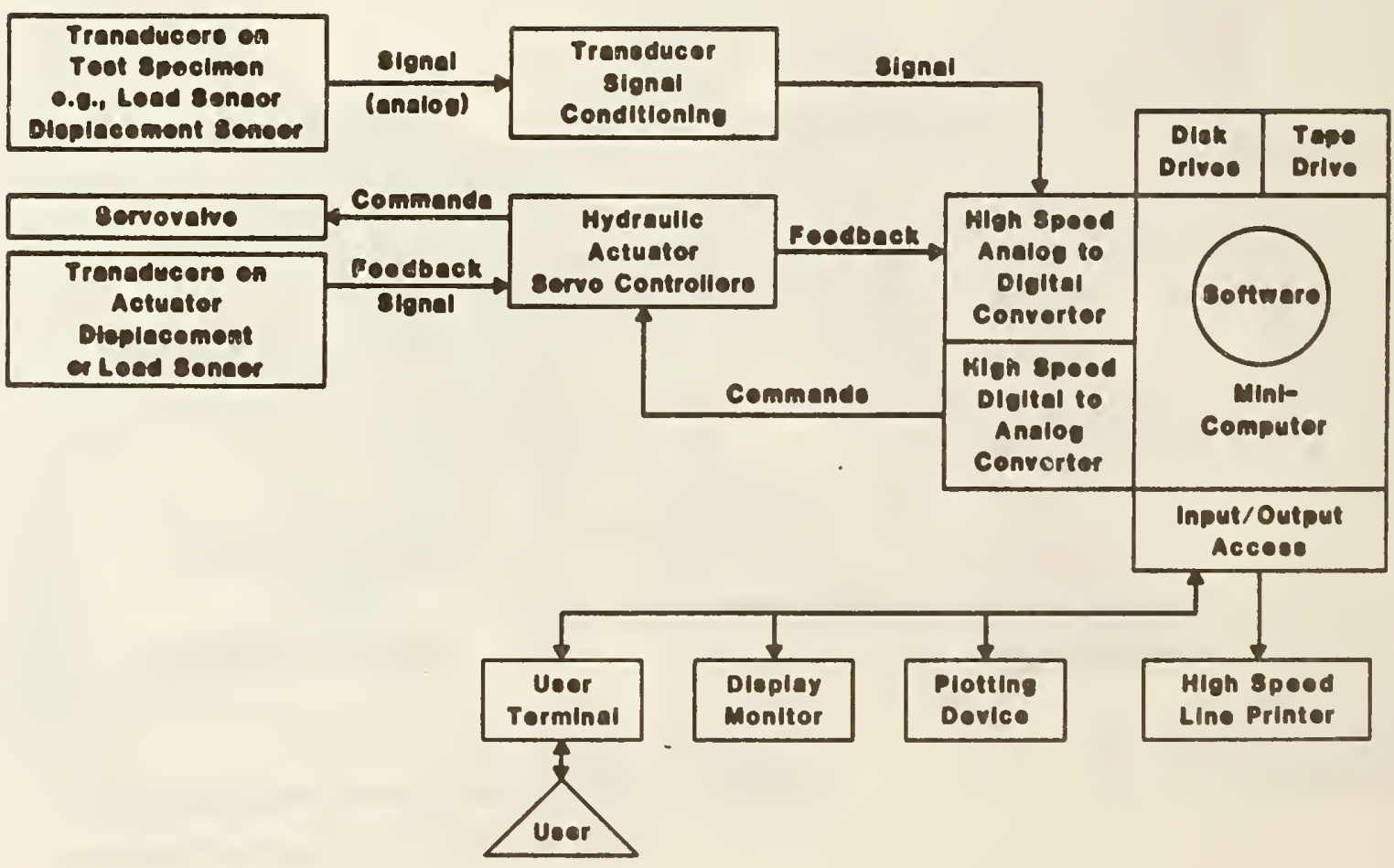

Figure 1.5. Control system schematic 


\section{REACTION SYSTEM}

The reaction system is composed of two parts, a structural tie-down floor and two vertical buttresses (figure 2.1). The structural tie-down floor is a $1.8 \mathrm{~m}$ thick heavily reinforced concrete slab. The slab contains an embedded grid of steel beams to resist lateral forces. Anchorage points for connecting test fixtures to the slab are located in a grid $1.5 \mathrm{~m}$ on center. The anchorage points (figure 2.2) are flush with the slab surface and have two threaded sleeves which accept threaded high strength steel rods. Each anchorage point (using both sleeves) has a working capacity of $900 \mathrm{kN}$ in both the vertical and horizontal directions. The horizontal resistance is not provided by the threaded rod, but by direct bearing of shear sleeves which are concentric with the threaded rods.

The buttresses are vertical reinforced concrete structures which are post-tensioned both vertically and horizontally (figure 2.3). The orientation of the buttresses with respect to the loading system is shown in figure 1.2. The buttresses are H-shaped in plan view and are $4.9 \mathrm{~m}$ tall. There are through holes in each buttress at four heights to permit fastening of attachments. Each buttress has a design lateral load capacity of $1300 \mathrm{kN}$ applied $4.3 \mathrm{~m}$ above the slab surface. The capacity is based on a criterion of no vertical tension in the buttress. The moment resistance is principally provided by the twenty-eight vertical post-tensioned rods in each buttress. Each post-tensioned rod is terminated in the tie-down floor with a rock anchor. The rock anchors are made of a length of high strength steel rod embedded in an epoxy material with a coupler at the top to recelve the buttress rod. Each rock anchor/buttress rod assembly was proof tested to a load 30 percent greater than its design working load. 


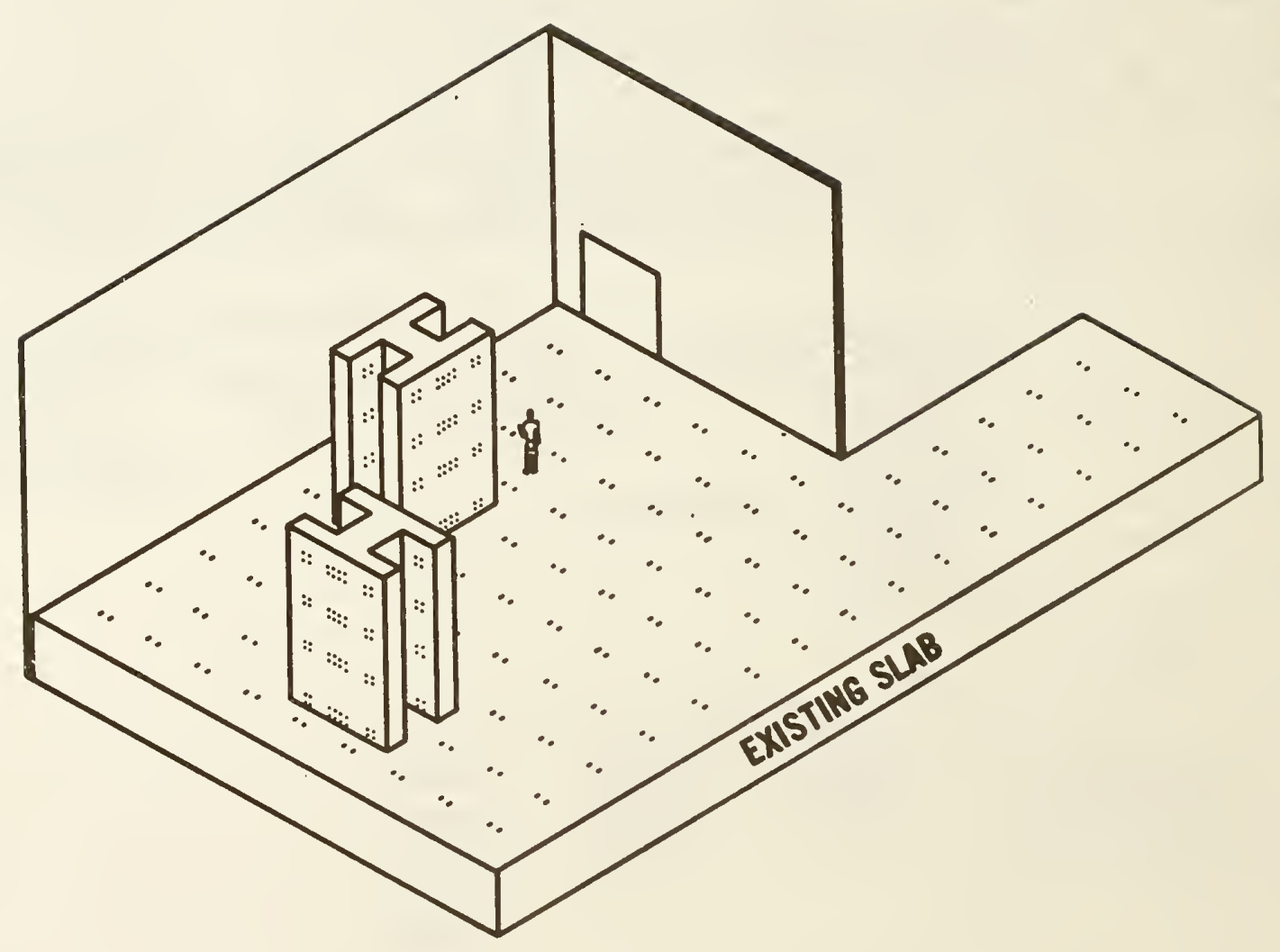

Figure 2.1. Components of reaction system 


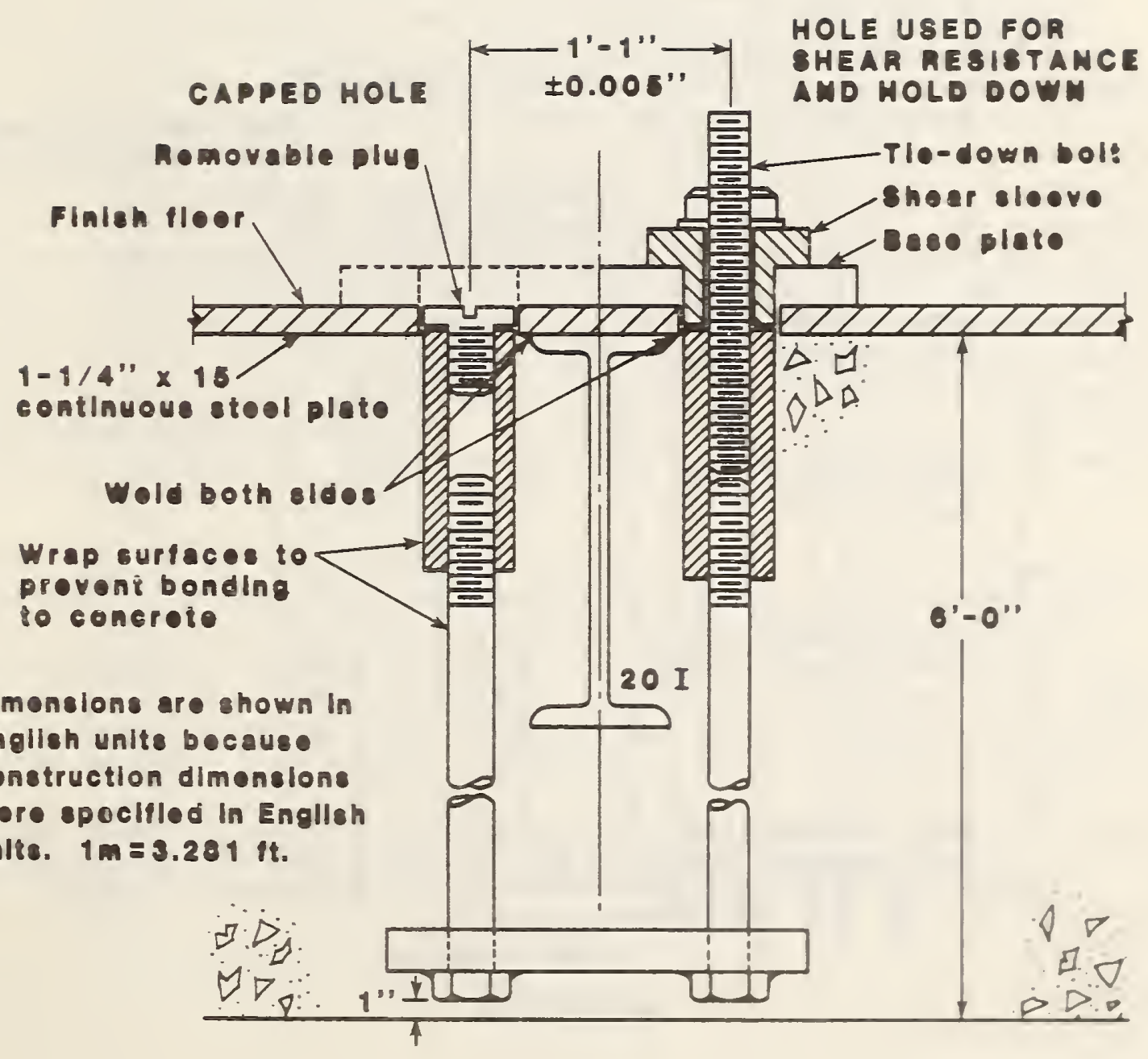

Figure 2.2. Floor-slab anchorage detall 


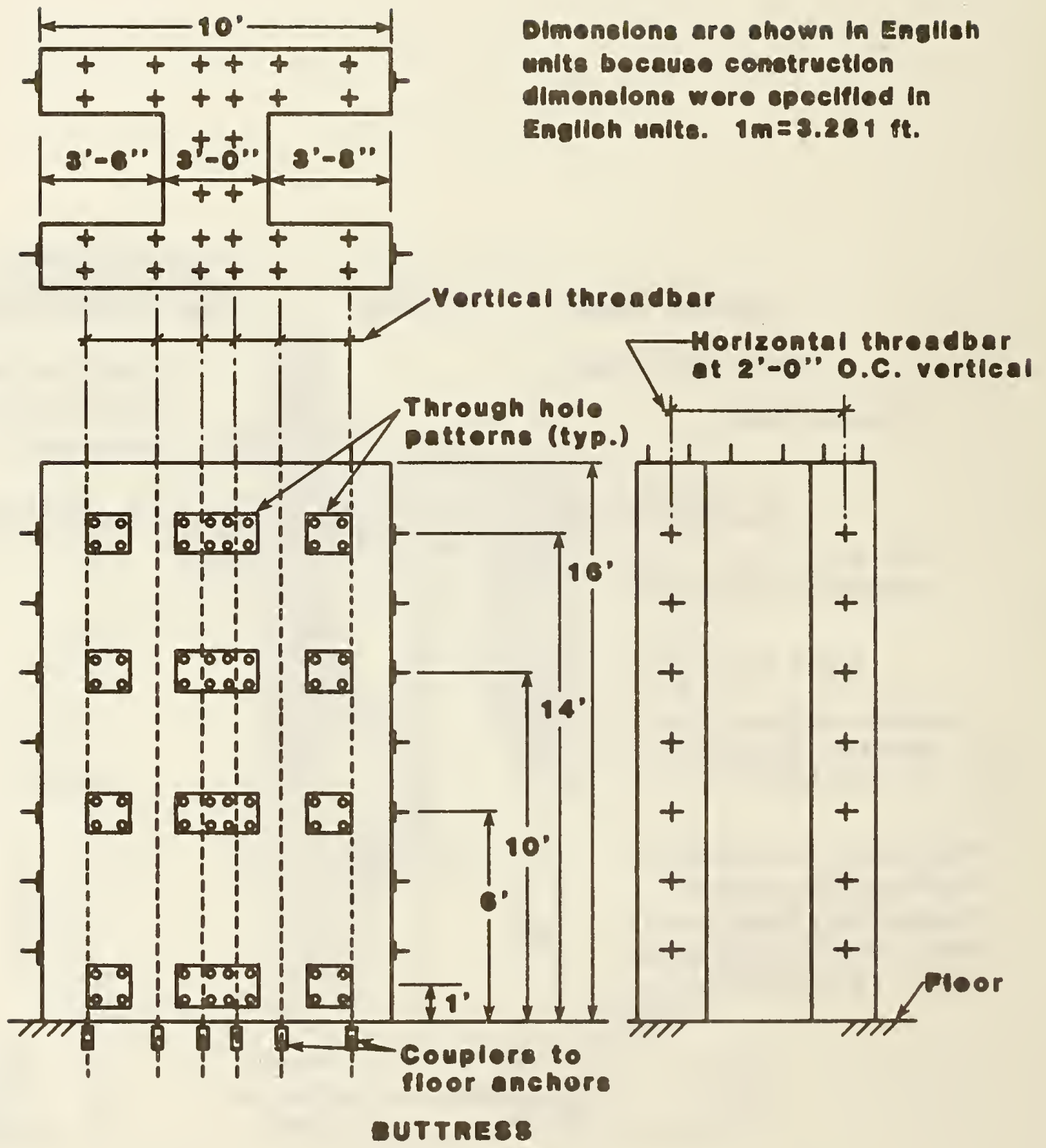

Figure 2.3. Buttress detail 


\section{LOADING SYSTEM}

The loading system consists of seven double-ended hydraulic actuators which are part of a general closed-loop, servo-controlled hydraulic system. Support equipment includes a hydraulic power supply (pump), servo-controllers (discussed in section 5.4), and miscellaneous wires, hoses, and other items necessary to interconnect the different parts of the system.

A hydraulic actuator, in its simplest form, is a hydraulic cylinder with a piston which can extend and retract. The movement of the piston is controlled by the volume of oil in the cylinder. A servo-controlled hydraulic actuator has an electrically controlled hydraulic valve to regulate the volume of oil in the cylinder. The hydraulic actuators used in the NBS/TTF have additional components not found on simple hydraulic actuators. A typical hydraulic actuator used in the loading system is shown in figure 3.1 with the major components identified. The major components are the servo valve, service manifold, piston, load transducer (load cell), internally mounted displacement transducer (LVDT-linear variable differential transformer), and swivel end fittings. The servo valve has a flow rating of 3.36 cubic meters per second. The service manifold performs several functions. It filters the oil, controls oil volume fluctuations, permits operation of the actuator in a low-pressure condition and, when needed, prevents the piston from moving even in the absence of an external hydraulic pressure source. The load transducer measures the load applied to the actuator as a result of piston action. The displacement transducer is rigidly mounted inside the body of the actuator and measures the piston movement relative to the actuator body. The swivel end fittings permit relatively unrestrained rotation over an angle of 270 degrees in the plane of the swivel and approximately 10 degrees in the other planes. In short, the swivel can rotate in all three dimensions.

Each of the four vertically installed hydraulic actuators has a total piston movement range of $300 \mathrm{~mm}$. The load capacity of each vertical actuator is 670 $\mathrm{kN}$ in either tension or compression. Each of the two horizontal actuators which are parallel to the north-south axis of the NBS/TTF has a stroke of 300 mm and a load capacity of $380 \mathrm{kN}$ in either tension or compression. The single horizontal actuator installed along the east-west axis of the facility has a stroke of $150 \mathrm{~mm}$ and a load capacity of $975 \mathrm{kN}$ in either tension or compression.

The hydraulic power supply is a 4.5 cubic meters per second, variable volume pump rated at a pressure of $34 \mathrm{MPa}$ but used at a pressure of $20 \mathrm{MPa}$. 


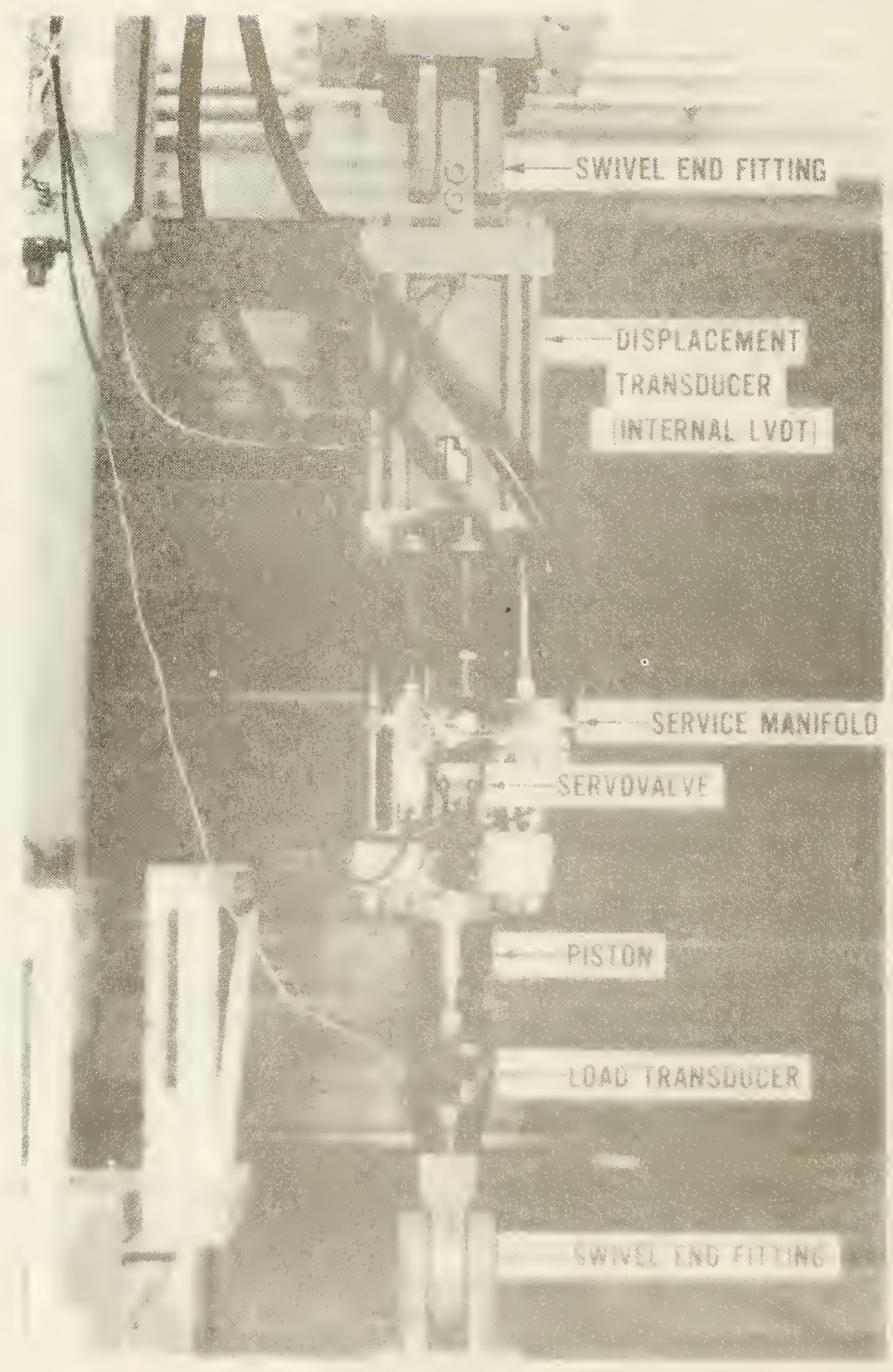

Figure 3.1. Hydraulic actuator components 


\section{LOAD DISTRIBUTION SYSTEM AND ACTUATOR POSITIONING BEAMS}

The load distribution system consists of upper and lower steel crossheads. Each crosshead is formed by two approximately $4 \mathrm{~m}$ long beams bisecting at a 90 degree angle. Each beam has a cross section in the shape of a flanged box. This shape was made by welding two heavy wide-flange structural shapes (W21 x 132) together along their butted flanges. Each crosshead surface is approximately $635 \mathrm{~mm}$ wide and is pierced along its length with holes through which test specimens can be bolted to the crosshead. Each crosshead is heavily stiffened by vertical plates $6 \mathrm{~mm}$ thick welded to both the top and bottom flanges and the web of each wide-flange beam. The lower crosshead is bolted to the tie-down floor and held stationary

The horizontal hydraulic actuators are attached to the reinforced concrete buttresses by means of steel positioning beams. A typical beam is shown in figure 4.1. The use of slotted holes and an incremental round hole spacing permits a continuously variable height adjustment. The limits of the adjustment, however, are dictated by the hole pattern of the buttress and are approximately $1.2 \mathrm{~m}$ and $4.3 \mathrm{~m}$ above the slab surface. 


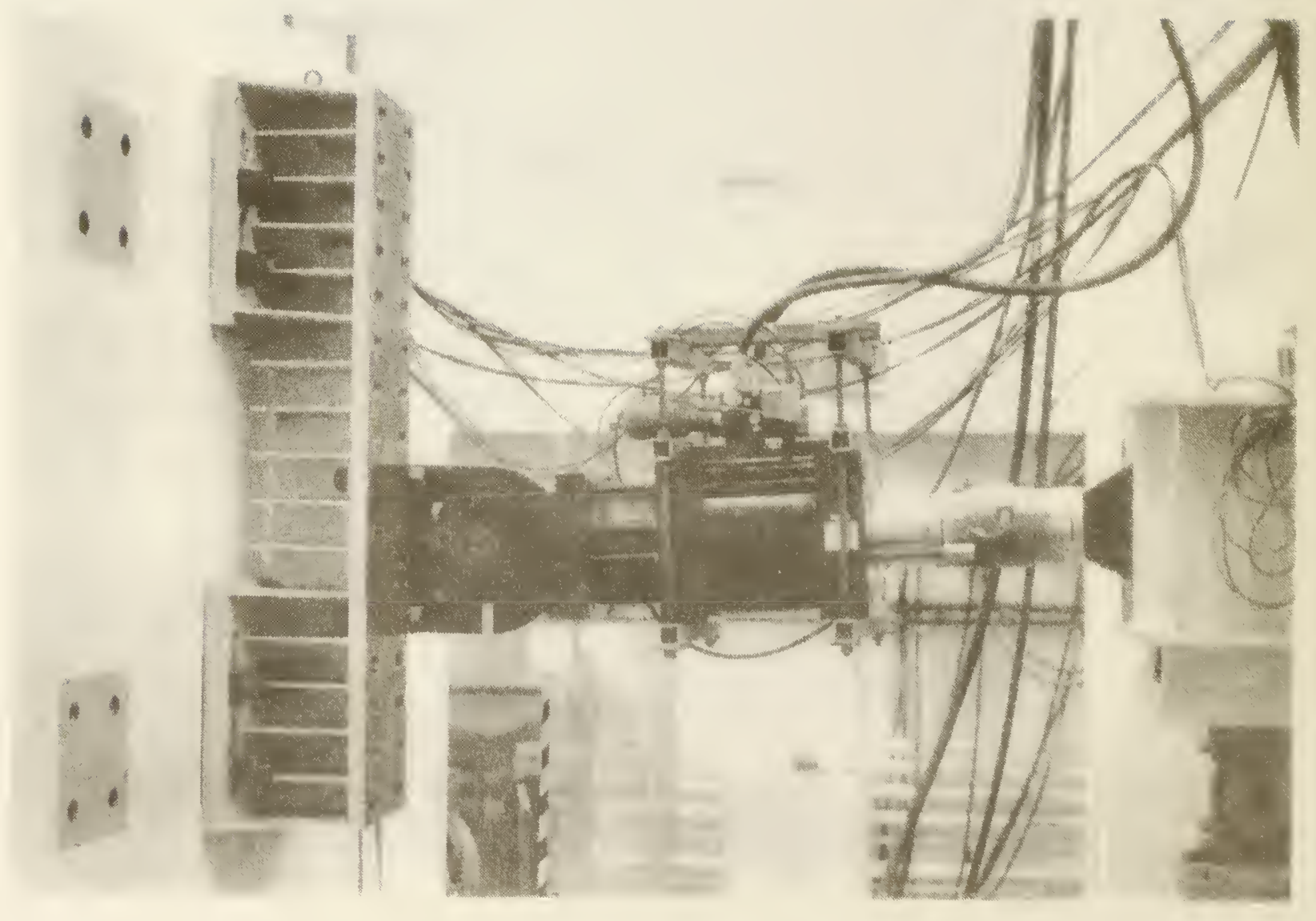

Figure 4.1. Actuator positioning beam 
The control system coordinates the activities of the NBS/TTF including hydraulic actuator piston movements, test specimen data acquisition, and data display. The control system consists of a minicomputer with the usual peripherals, an analog-to-digital converter, a digital-to-analog converter, seven servo controllers, and computer software. A schematic of the system is shown in figure 1.5. This section discusses the hardware while the next section discusses the computer software.

\subsection{MINICOMPUTER AND PERIPHERALS}

The minicomputer system is based on a moderately powerful, 16-bit word length, central processing unit (CPU). Enhancements to the CPU include memory management with 18-bit addressing, hardware floating point operations, and hardware integer multiply and divide. The main memory contains 256 kilobytes ( $\mathrm{kb}$ ) of MOS memory which is the maximum possible for 18 bit addressing. Permanent mass storage is provided by three hard media disk drives and one tape drive. There are currently about 18 megabytes (Mb) of disk storage with all but $5 \mathrm{Mb}$ contained in removable media disk drives. The tape drive is an industry compatible nine-track unit supporting both 800 and 1600 bit per inch writing densities. Storage capacity on a tape is affected by several factors but, as a guide, $40 \mathrm{Mb}$ (10 million data points) can be recorded on a single $730-\mathrm{m}$ reel of tape.

The user interface includes several video display terminals, high-speed printing terminals, video graphic devices (including color), a flat-bed digital plotter, and a high-speed (300 line per minute) line printer. The video terminals are used for data display in both tabular and graphical form. The printing terminals are primarily intended as user input devices during a test so that a copy of all user instructions is obtained. The flat-bed plotter is mainly used for post--test data plotting and the line printer is used to obtain a listing of all acquired data immediately after a test.

\subsection{ANALOG-TO-DIGITAL CONVERTER (ADC)}

The ADC is a high speed multiplexed converter with a sampling rate of 50,000 samples per second. It is connected to the minicomputer by Direct Memory Access such that the total system throughput is equal to the $50 \mathrm{kHz}$ converter sampling rate. The current system has provisions for 192 separate data channels. The $A D C$ has two levels of internal signal amplification (gain) to maximize the conversion resolution. The first gain is determined by interchangeable chips on the circuit boards with each channel being individually adjustable. The second gain is selected by computer instruction and can be set for each channel. The total gain applied to each channel prior to conversion is the product of the two gain levels. The total gain is variable in discrete steps between 1 and 20,000. Active signal filtering is performed on each channel with the cutoff frequency selected by interchangable chips on the circuit boards. The converter has a full-scale range of +10 volts with a digital representation 
provided by a 12-bit word. The resolution (not error) is 1 part in 4096 $\left(1 / 2^{12}=1 / 4096\right)$.

\subsection{DIGITAL-TO-ANALOG CONVERTER (DAC)}

The DAC can be accessed at CPU machine speed, but the rise and settle time is on the order of 5 microseconds. There is a total of eight DAC channels, seven of which connect to the servo-controllers. The DAC has a full-scale range of \pm 10 volts with a resolution of $1 / 4096$.

\subsection{SERVO-CONTROLLER}

Each hydraulic actuator requires a servo-controller to manipulate the actuator's servo valve. The servo-controller is basically an analog comparator. Its function is to constantly compare an analog command signal with an analog feedback signal and to manipulate the action of the hydraulic actuator's piston such that the difference between the command and feedback signals is zero. The difference between the command and feedback signals is called the error signal. The servo-controller uses the error signal to determine how the servo valve should be directing oil flow. The feedback signal is usually from a load transducer (load control) or a displacement transducer (stroke control). The command signal may be produced internally by the servo-controller and varied manually by the operator at the servo-controller itself or the command signal may be externally generated and varied such as through a DAC. For ease of operation, the servo-controller is calibrated such that the full-scale range of the command signal is equal to the full-scale range of the two feedback transducers. This procedure produces a direct one-to-one correspondence between a given command signal and the resulting feedback signal.

A simple example of servo-controller operation is described below. Assume that stroke (displacement) is the control feedback and the relation between piston movement and feedback voltage is $5 \mathrm{~mm}$ per volt with piston extension producing a positive change in voltage. Consider that the actuator's piston is extended $10 \mathrm{~mm}$ from its fully retracted position and that this extension corresponds to a feedback signal of +2 volts. If the command signal is set to +2 volts then there is no piston movement. If the command signal is changed to +1 volt then an error signal of -1 volt is produced. The error signal is translated by the servo controller into a current signal to the servo valve which causes oil to flow into and out of the actuator such that the piston retracts $5 \mathrm{~mm}$. There is no further piston movement until the command signal in changed and an error signal generated. Within the load capacity of the actuator the piston will move to satisfy the command signal regardless of the load developed as a result of the movement. The load produced by piston movement is determined by the stiffness of the objects attached to the actuator. If load control is used then the piston moves to whatever position is required (within its stroke limits) to produce the desired load. 
All functions associated with hydraulic actuator control and data acquisition, manipulation, and display both during and after a test are computer-based. A large collection of computer software has been developed by NBS researchers to perform the various tasks. In general, all software is user oriented, making it possible for relatively inexperienced operators to use the NBS/TTF. However, the complexity and sophistication of the overall NBS/TTF (both hardware and software) require that a trained and experienced operator must oversee the planning and execution of any test.

\subsection{ORGANIZATION}

The software which actually supports the performance of a test is all that will be discussed in this report. Post-test data manipulation and display software is of a general nature and not exclusive to the NBS/TTF. It is worthwhile to note, however, that there is extensive software available to support the posttest analysis of data produced by tests in the NBS/TTF.

The software which supports the actual testing of a specimen in the NBS/TTF is called TEX which is an acronym for Test EXecutive. TEX is not a single program, but a collection of separate executäble programs (tasks) which operate concurrently in a multi-task environment. The specific needs of a test determine which programs are actually used, but the selection and operation of the various programs is controlled by the software and not by the operator. The use of multi-tasks permits fast response to changing test conditions by enabling the various tasks to be prioritized. The assignment of priorities enables TEX to allocate more computer resources to those tasks which require them and to do it on a real-time basis. There are also pre-test computer programs which support the use of data bases necessary to the execution of TEX. In addition, there is software tailored to the manipulation of the NBS/TFF during test specimen installation.

The functions of TEX can be divided into three main categories: 1) data acquisition and storage, 2) hydraulic actuator control, and 3) data display. In actual practice the functions are not as distinct, but for purposes of the subsequent discussion the division is a convenient classification.

\subsection{DATA ACQUISITION AND STORAGE}

The function of data acquisition and storage is common to all laboratory test1ng. TEX requires several separate data acquisition processes, but this discussion is limited to that which pertains to data acquired by user request. The operator predefines the ADC channels which will be sampled during the test but the channel definition may be changed during the test. The same data base can be used for many tests. The operator specifies acquisition rate and can turn the acquisition of data on and off. The acquired data are stored as decimal voltages and the amount of data which can be acquired is limited only by the permanent storage space (disks and tape) available. The user does not have 
access to the stored decimal voltage during a test, but to permit data plotting and display during a test a second form of data storage is provided. A certain amount of permanent storage is allocated to a data pool. The same pool is used for each test so the information in the pool exists only during a test. TEX processes the acquired data on a time avallable basis to produce data in engineering units (reduced data) and stores these data in the data pool. The user may access the data pool to produce graphical or tabular displays of the acquired information. The data in the pool can be algebraically manipulated and edited to produce data displays using almost any possible combination of data.

\subsection{HYDRAULIC ACTUATOR CONTROL}

The computer software which controls the individual hydraulic actuators is complex, but the use of the software is simple. The operator need not consider the individual actions of the actuators. Instead, the operator defines global actions of the upper crosshead. The global actions are defined in terms of three easily visualized global directions which are north-south, east-west, and vertical. The lateral directions, north-south and east-west, are aligned with the two intersecting arms of the crosshead prior to crosshead movement. Each of the six degrees of freedom of the upper crosshead is defined by the operator by simply specifying values for the dof in terms of either a force (moment) or displacement (rotation). The specified value denotes whether a particular degree of freedom is displacement or load controlled. The method of control can be changed by simply specifying the desired control value. For example, the vertical translation degree of freedom may be defined as load control with the software required to maintain $50 \mathrm{kN}$ of vertical compressive force on the test specimen. The vertical displacement of the crosshead is then automatically varied by whatever amount is required to maintain $50 \mathrm{kN}$. Simultaneously, the translation in the north-south direction could be defined as 2 $\mathrm{mm}$ in displacement control. The software would then direct the hardware to move the crosshead $2 \mathrm{~mm}$ in the north-south direction while still maintaining 50 $\mathrm{kN}$ vertically. The software accounts for the effect of geometry changes caused by crosshead movement and resolves all actuator piston displacements and imposed forces into components acting in the global directions.

\subsection{DATA DISPLAY}

The data display function described in this section is the real-time data monitor. The display capabilities associated with user specified data acquisition were discussed in section 6.2. It is important that the operator have certain test specimen data available on a continuously updated basis. The operator can more readily verify proper test conduct and alter loading conditions if required. It would be extremely wasteful of permanent storage space to acquire and store all of the information needed to produce updated data display. For this reason, TEX includes a monitor capability which provides a real-time display of user specified data channels. The data are not stored, but only updated on a video display terminal. The data displayed by the monitor are reduced data and include corrections for excitation voltage fluctuations, gage factor, and temperature effects as specifled by the operator. The data channels actually displayed may 
be selected by the operator prior to the test and changed at any time during the test. An alternative to the reduced data format is the display of uncorrected decimal voltage values. This format is useful to verify that transducers are operating properly. 


\section{REMARKS}

The NBS/TTF is an addition to the existing structural testing laboratories and complements the currently available capabilities. The primary enhancement to structural testing provided by the NBS/TTE is its ability to control the movements (translations and rotations) of a test specimen in three orthogonal directions. While the NBS/TTF is primarily devoted to research on improving the resistance of structural elements subjected to earthquake loadings, its usefulness extends into other areas of structural research including the effects of wind loadings on structural elements. 


\section{ACKNOWLEDGEMENT}

The authors wish to thank Dr. John Gross, Dr. Spencer Wu, Dr. E. V. Leyendecker, and Dr. Len Mordfin for their careful review of this report and their constructive comments. 
APPENDIX: A PICTORIAL DESCRIPTION OF THE CONSTRUCTION OF THE NBS/TTF

Figure A.1. Laboratory prior to construction

Figure A.2. Drilling holes in tie-down floor for rock anchors

Figure A.3. Proof-testing an installed rock anchor

Figure A.4. Rock anchor after removal from tie-down floor

Figure A.5. Roughened outline of buttress cross-section

Figure A.6. Arrival of steel crossheads

Figure A.7. Fabrication of buttress flange reinforcement

Figure A.8. Erection of buttress flange

Figure A.9. Buttress reinforcement in place

Figure A.10. Pumping of buttress concrete

Figure A.11. Placement of buttress concrete

Figure A.12. Removal of buttress forms

Figure A.13. Installation of lower crosshead

Figure A.14. NBS/TTF nearing completion 


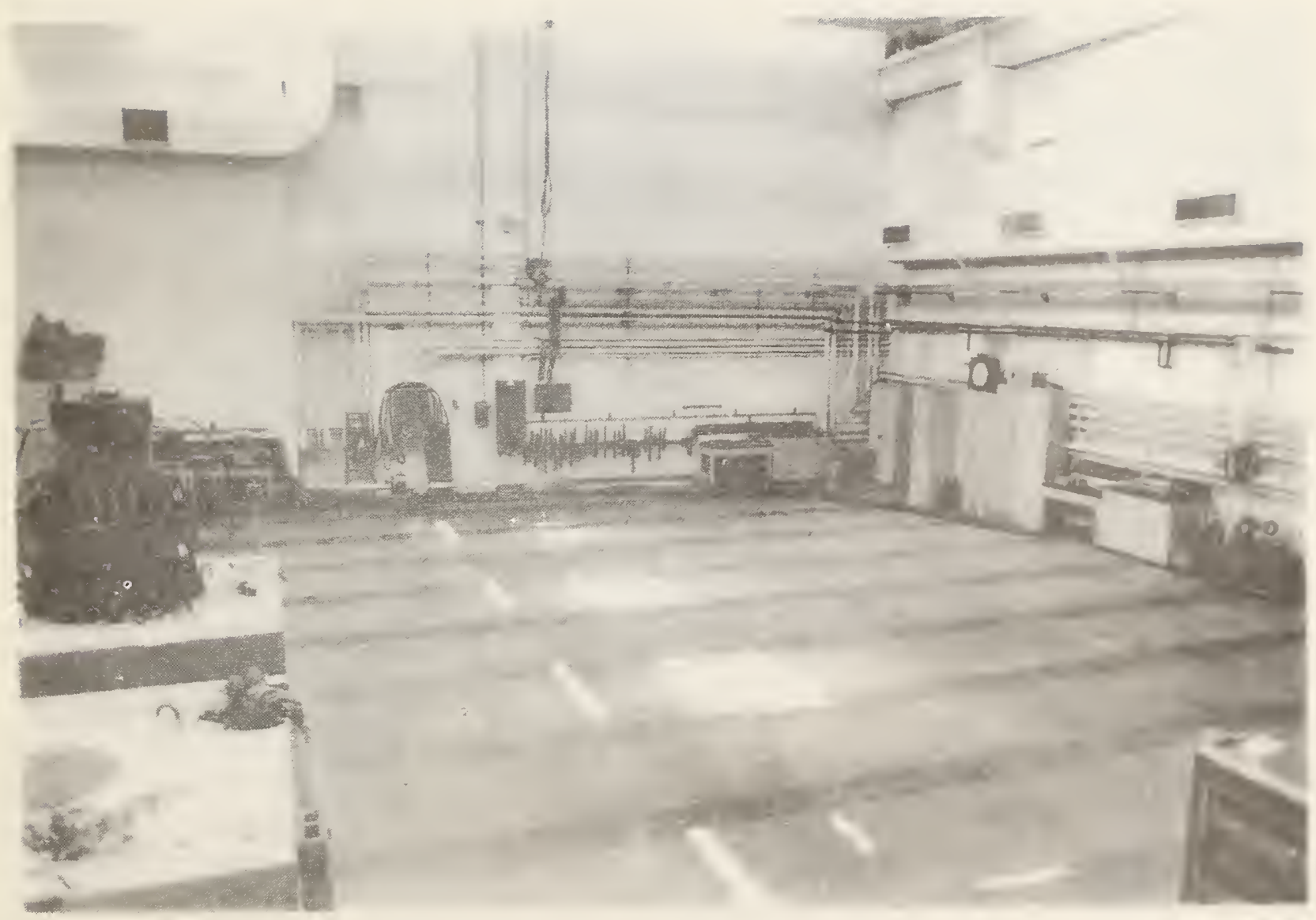

Figure A.1. Laboratory prior to construction 


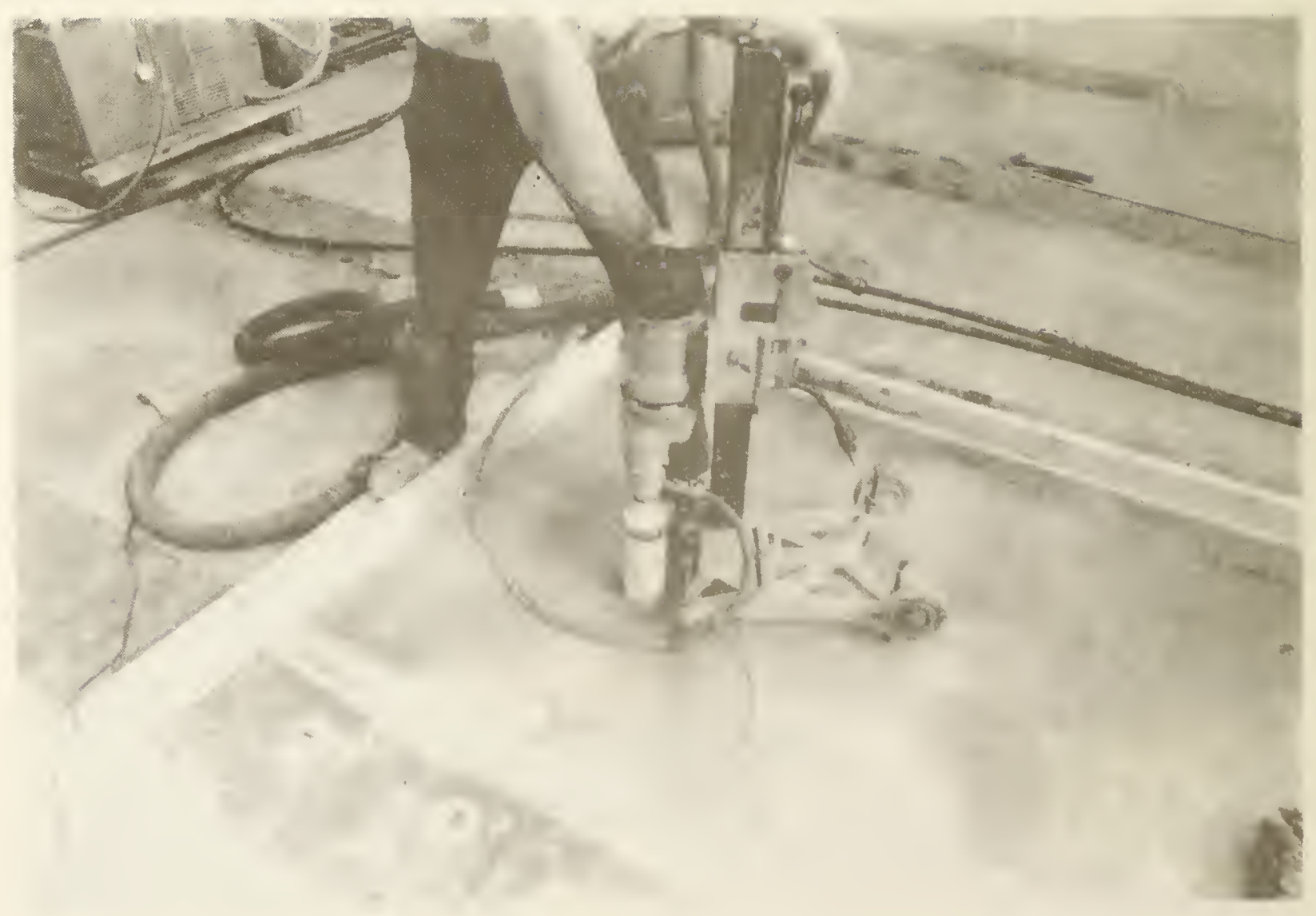

Figure A.2. Drilling holes in tle-down floor for rock anchors 


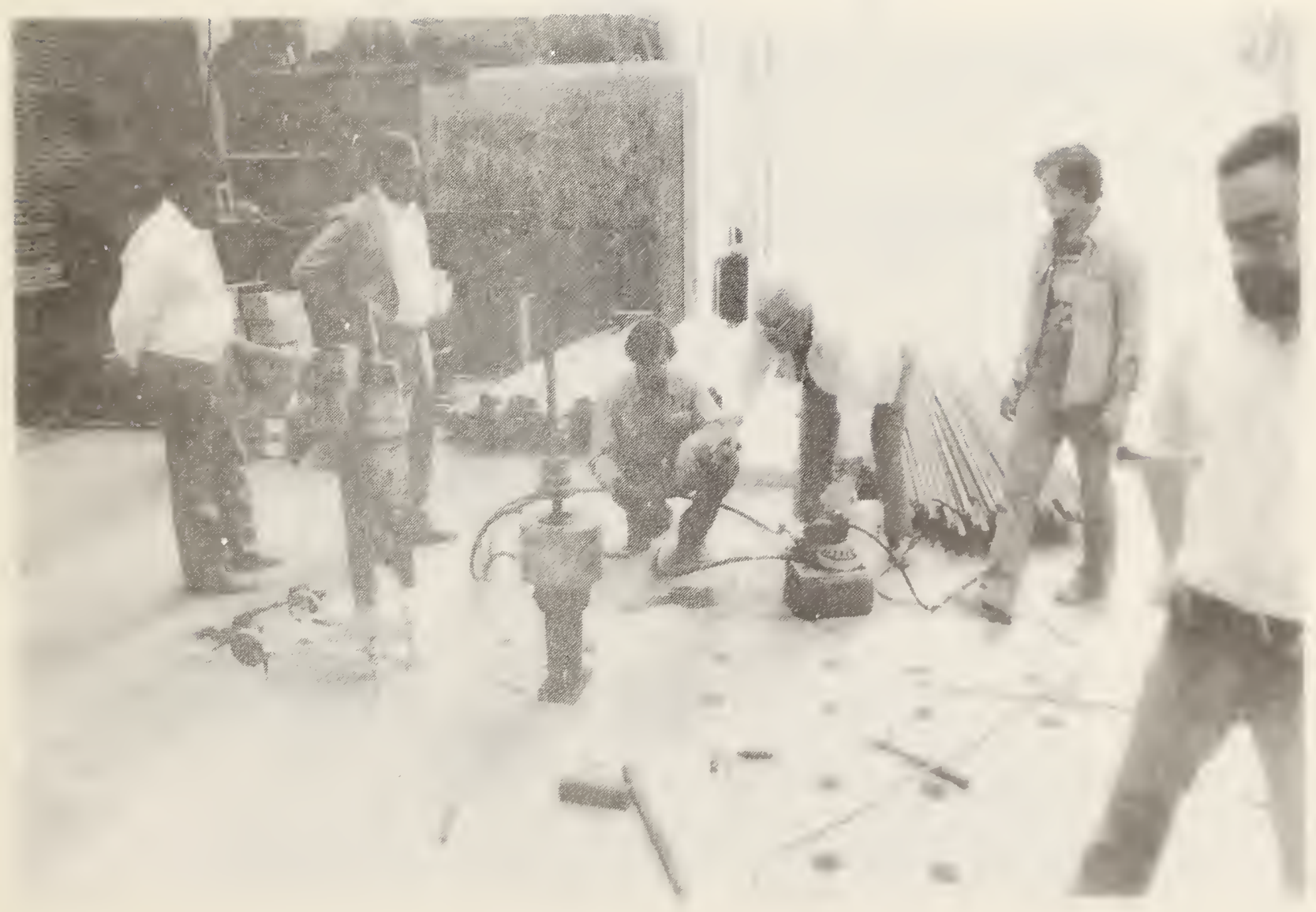

Figure A.3. Proof-testing an installed rock anchor 


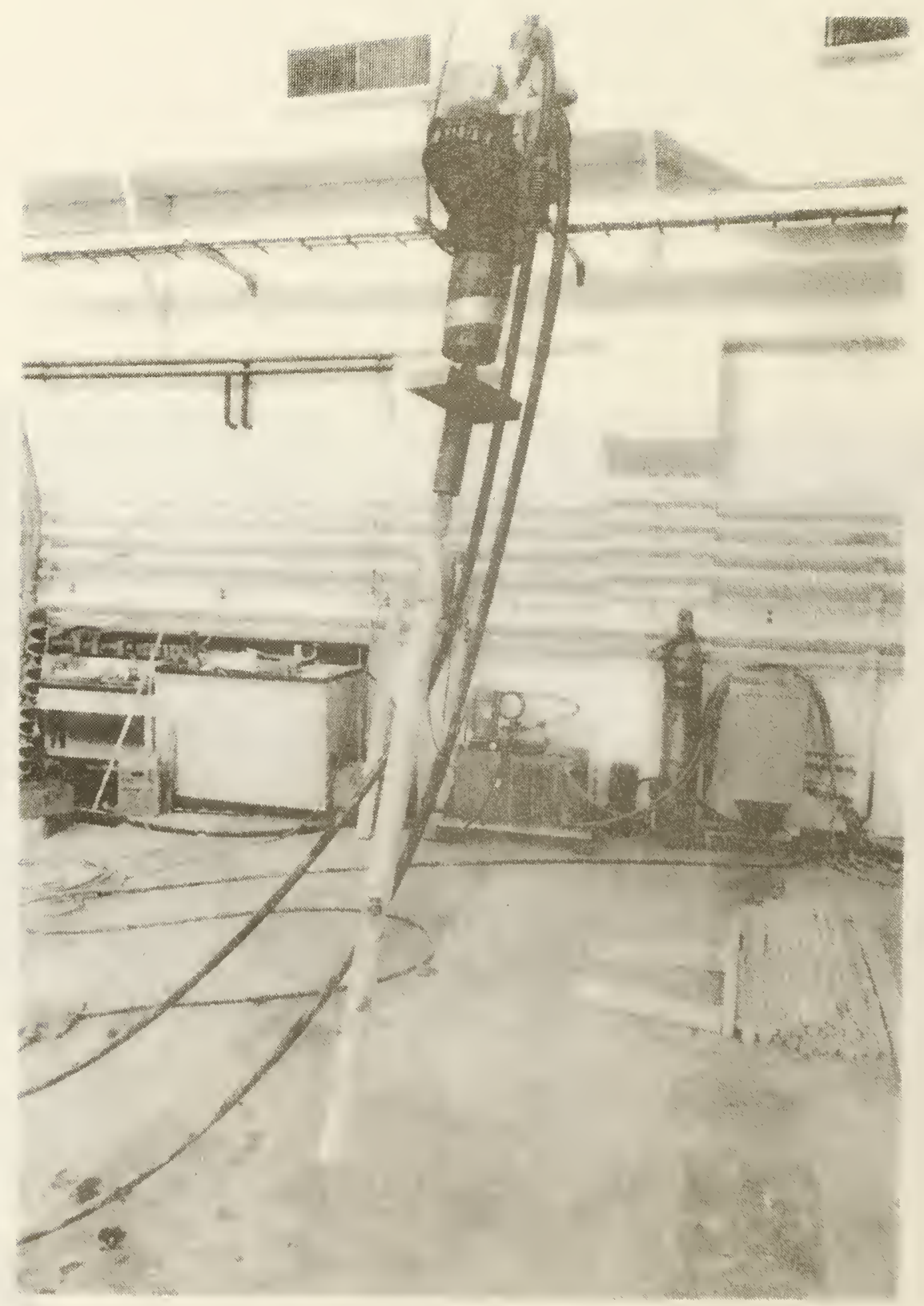

Figure A.4. Rock anchor after removal from tie-down floor 


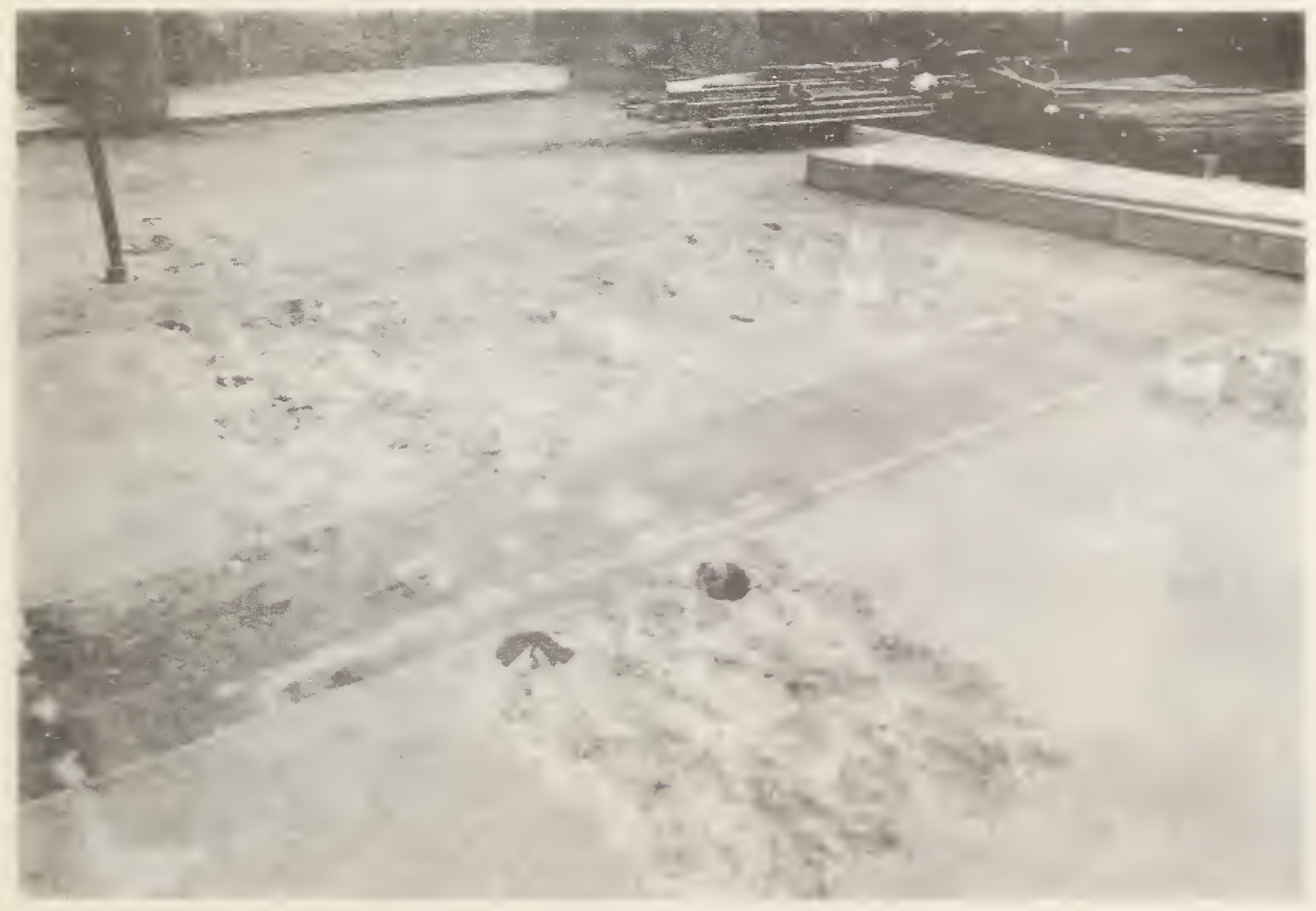

Figure A.5. Roughened outline of buttress cross-section 


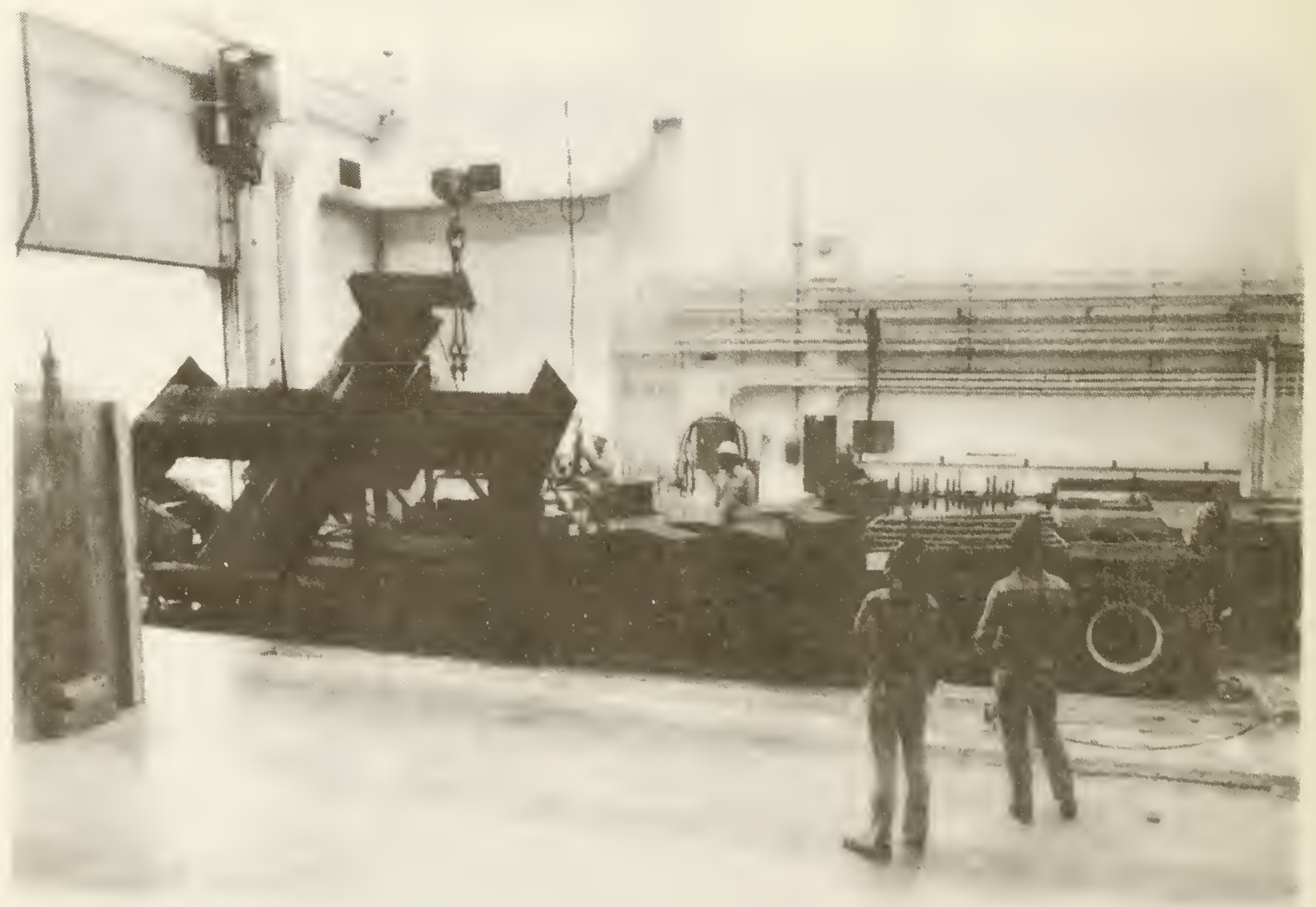

Figure A.6. Arrival of steel crossheads 


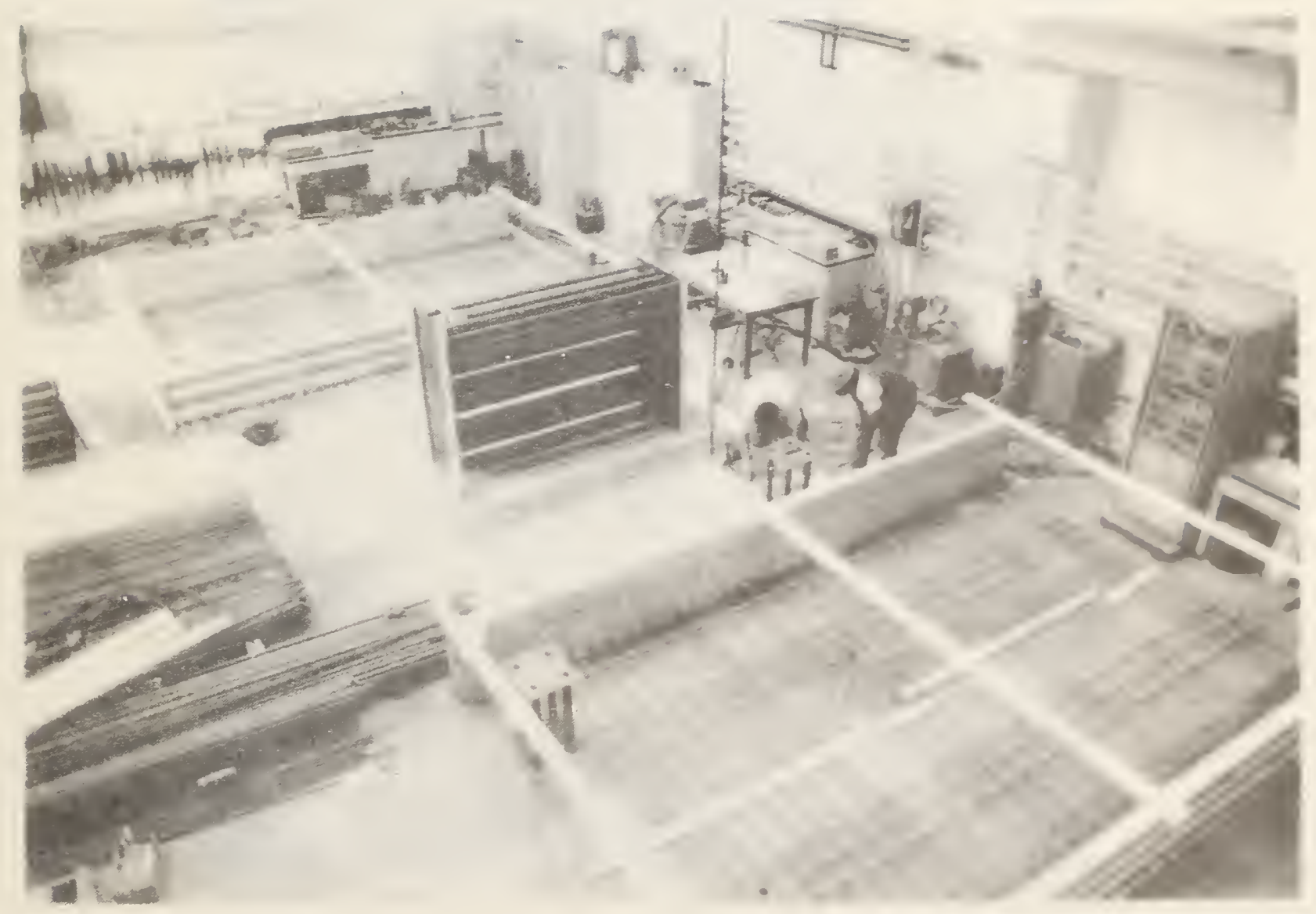

Figure A.7. Fabrication of buttress flange relnforcement 


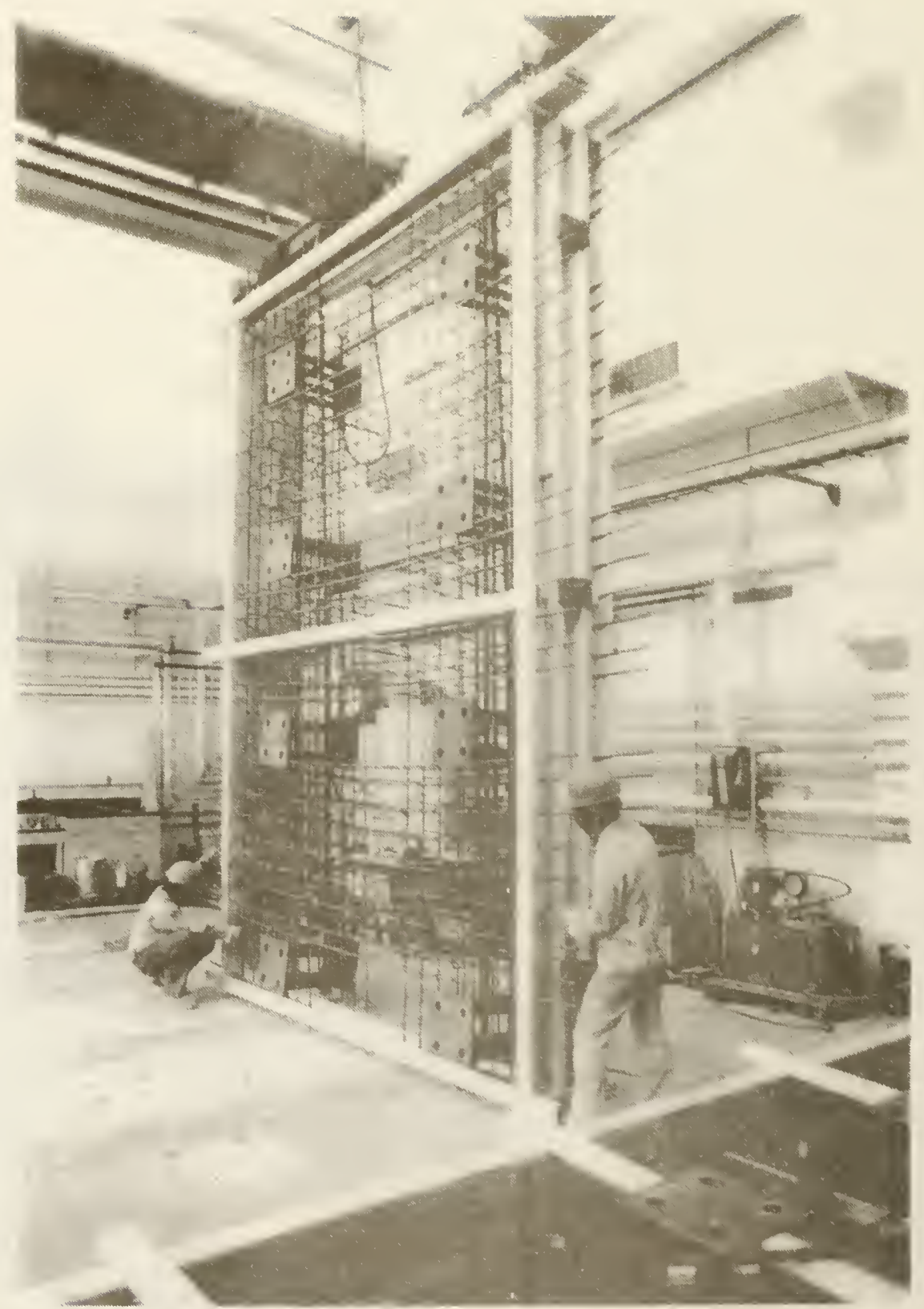

Figure A.8. Erection of buttress flange 


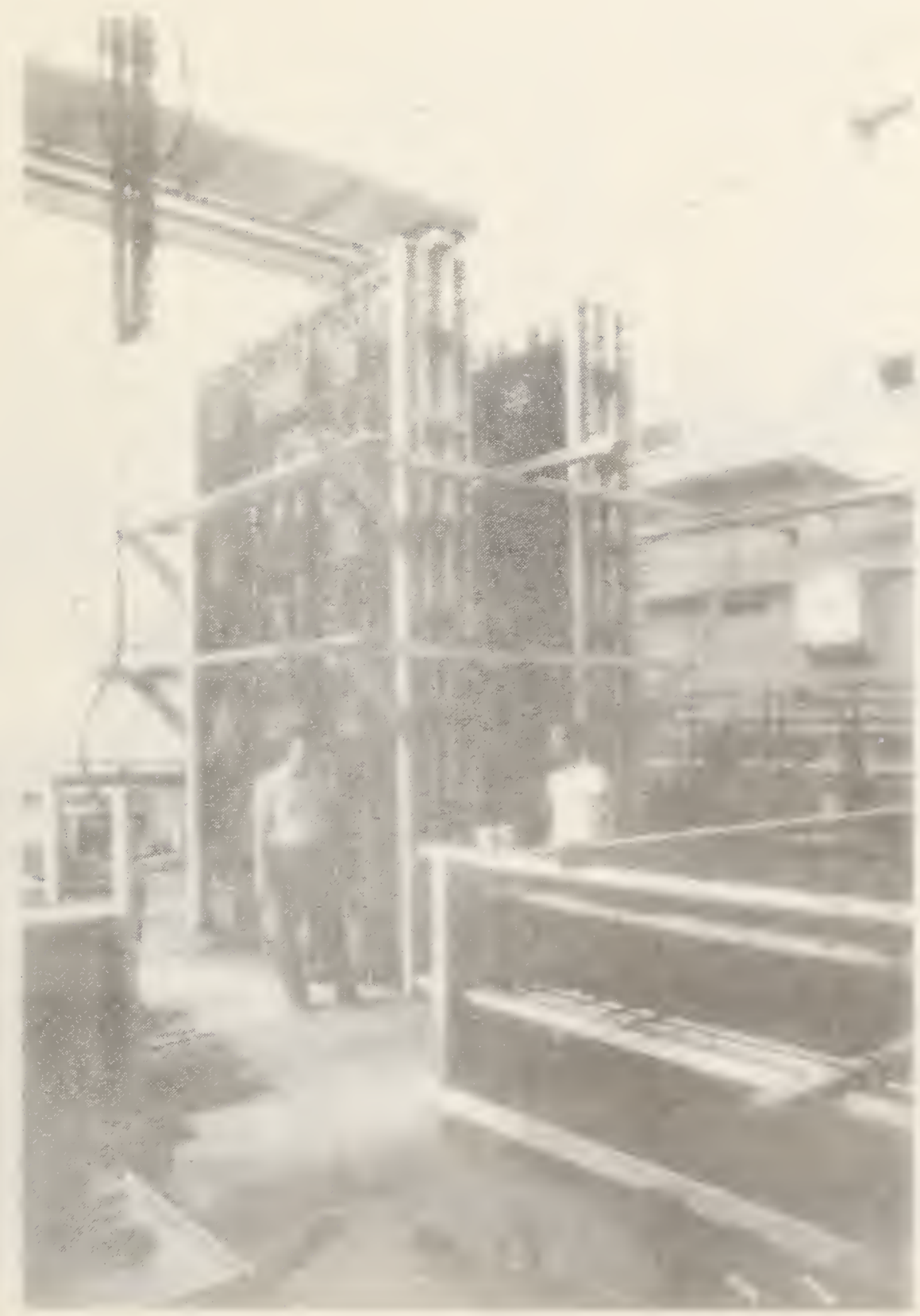

Figure A.9. Buttress reinforcement in place 


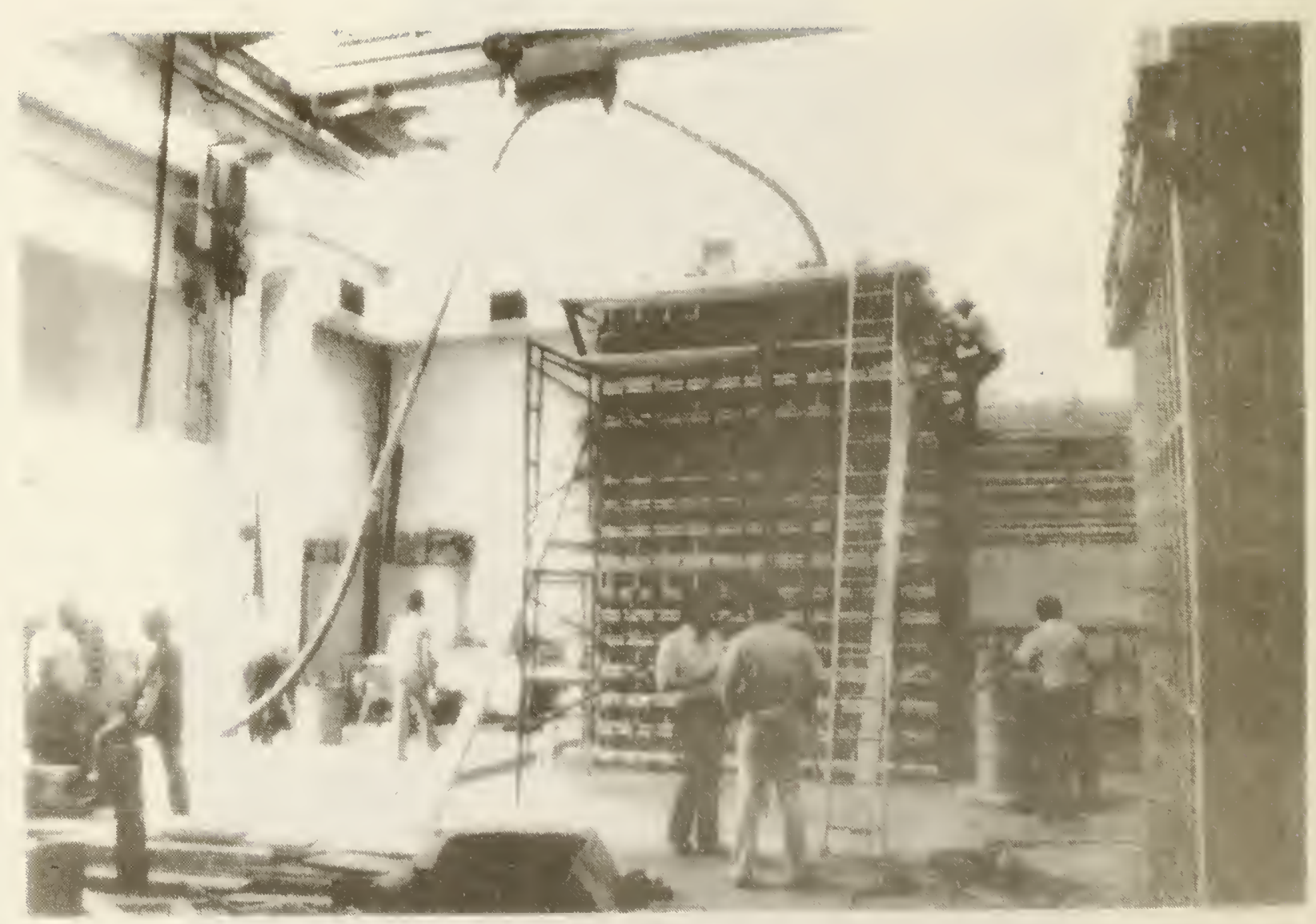

Figure A.10. Pumping of buttress concrete 


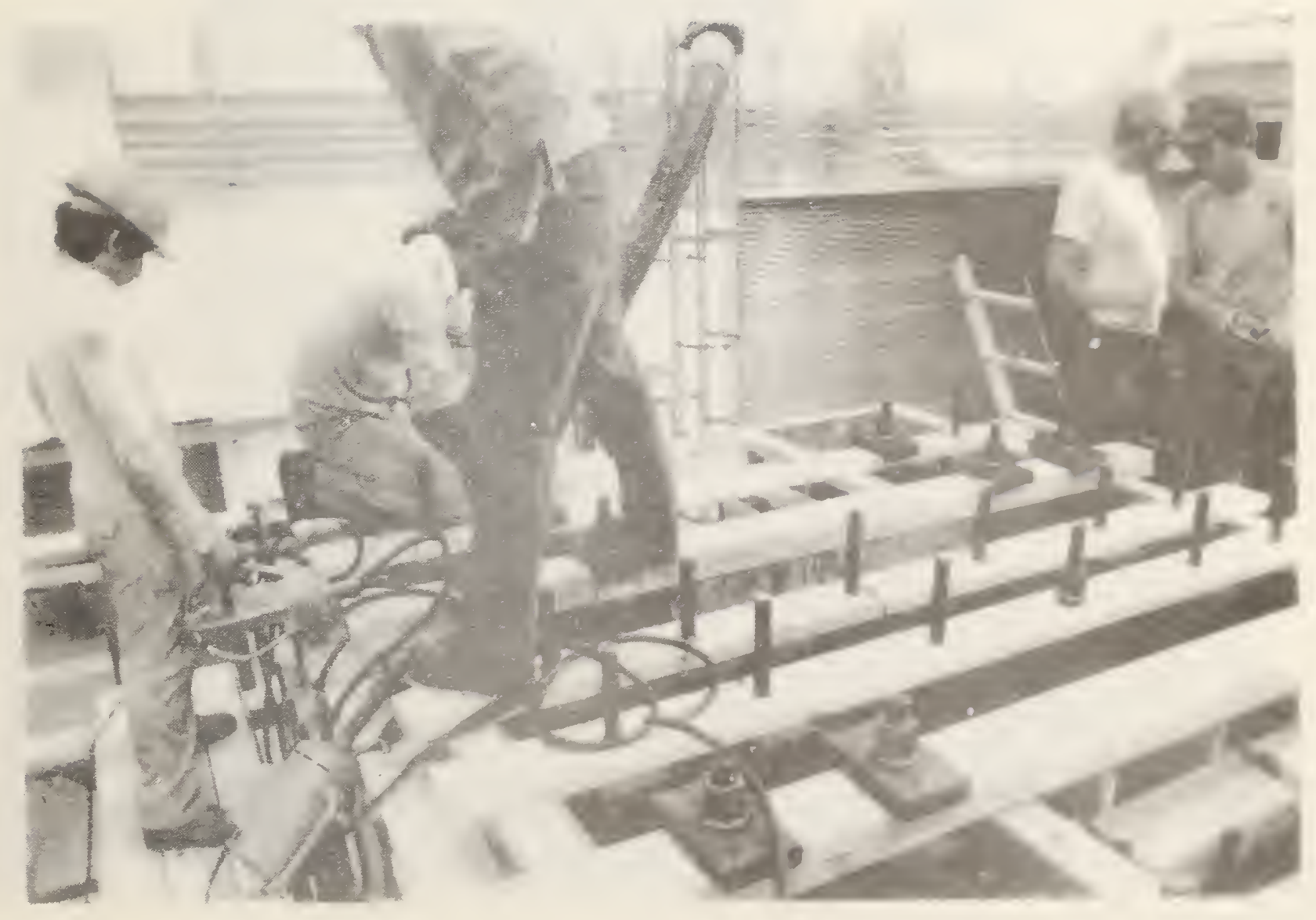

Figure A.11. Placement of buttress concrete 


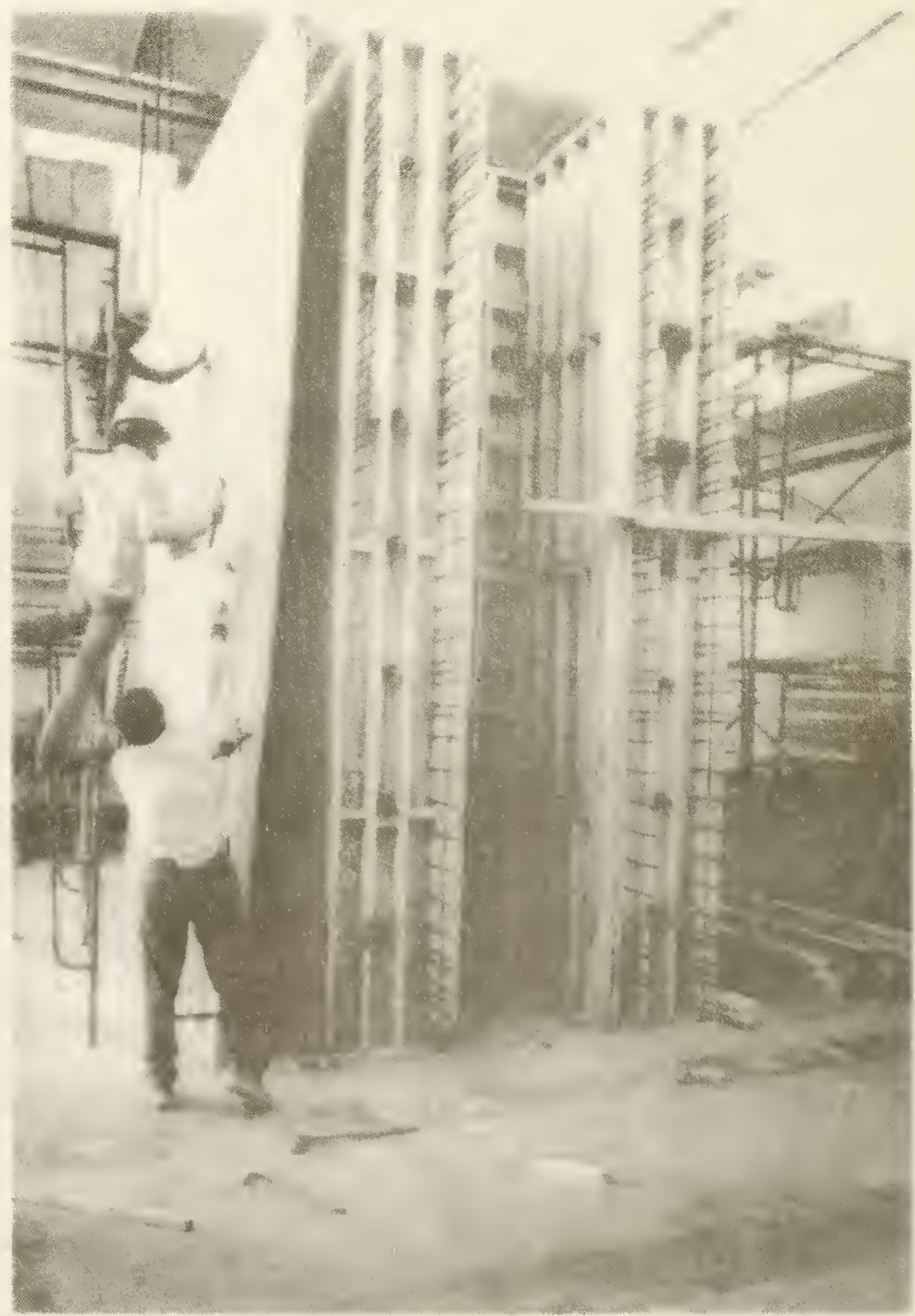

Figure A.12. Removal of buttress forms 


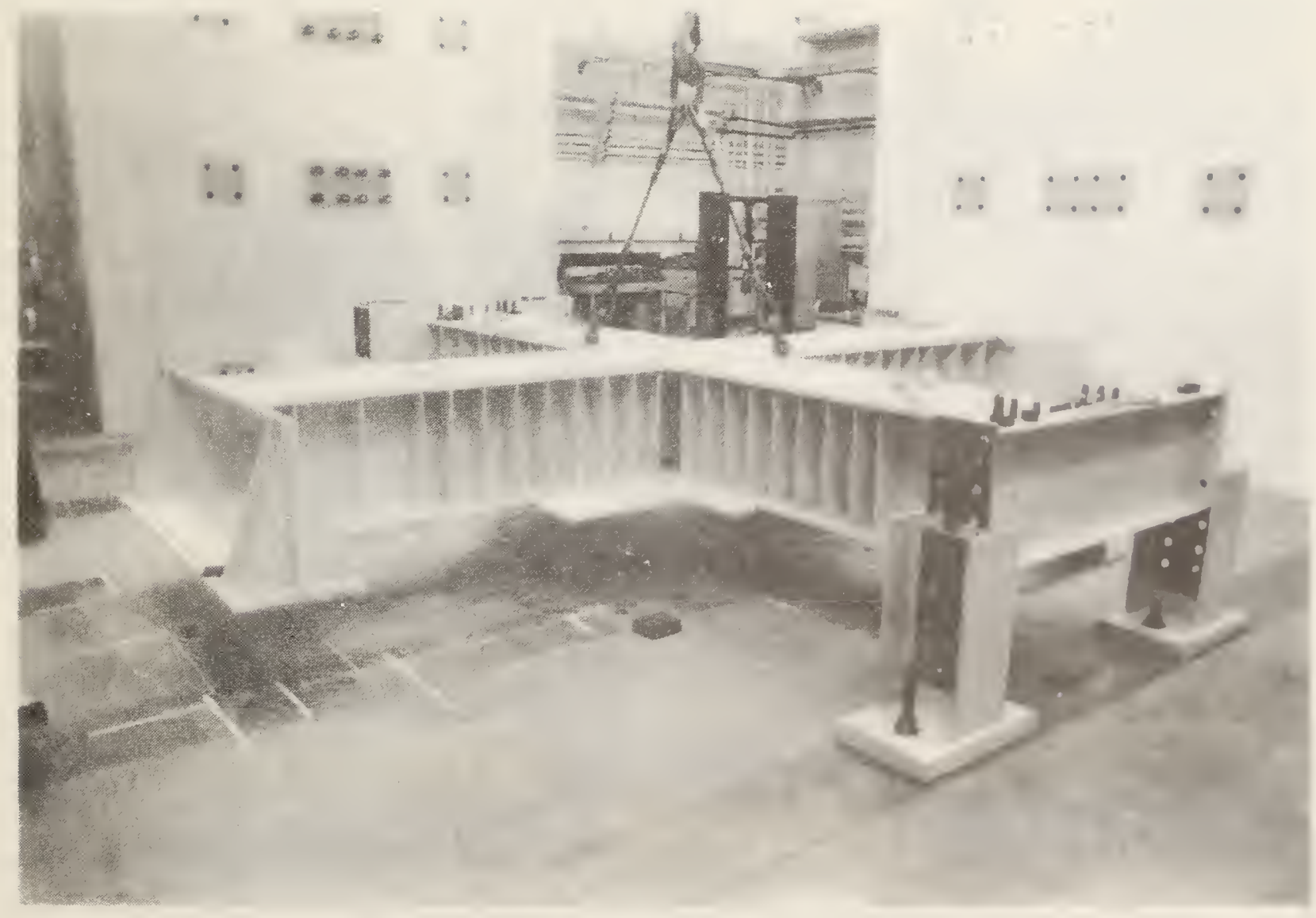

Figure A.13. Installation of lower crosshead 


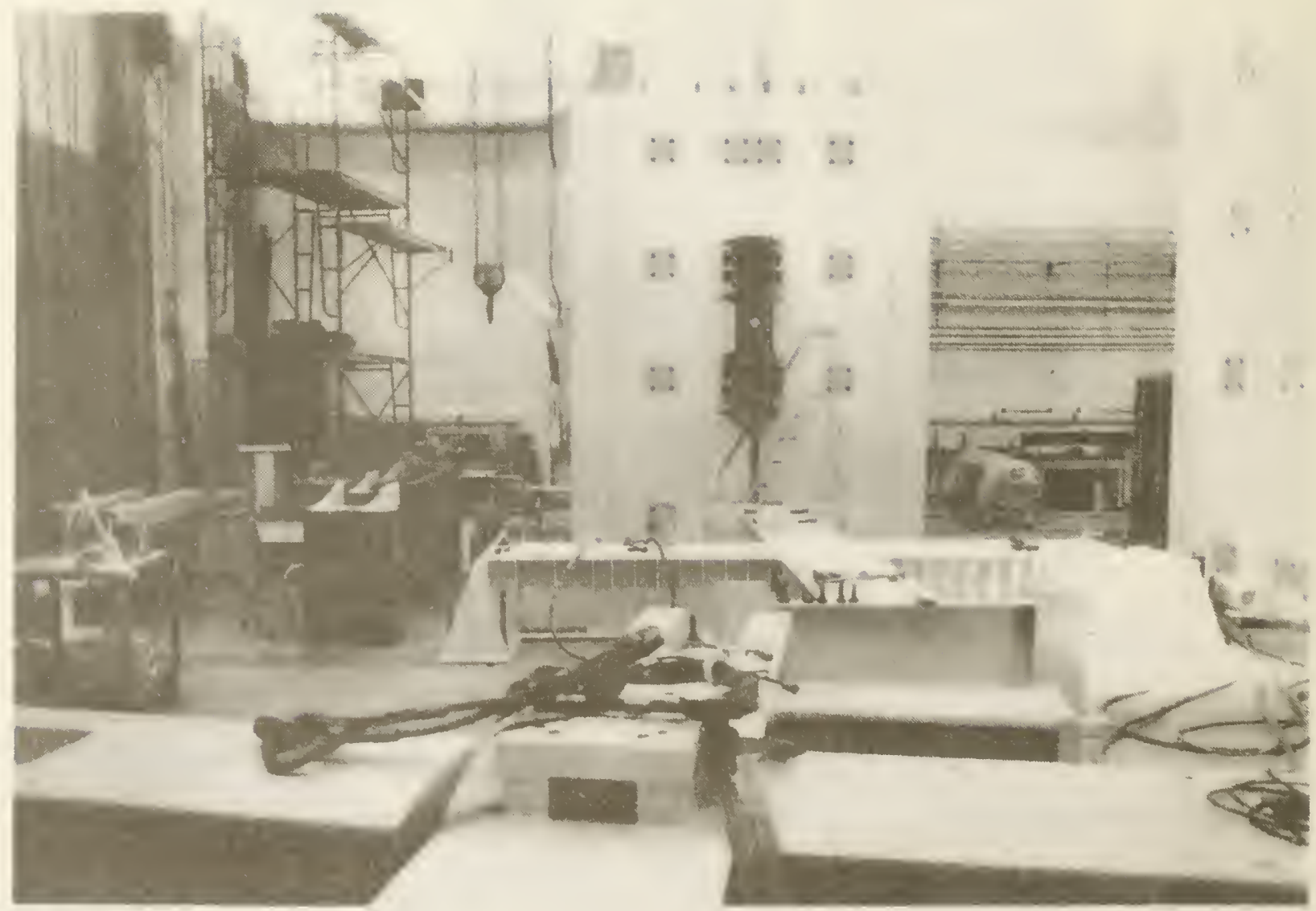

Figure A.14. NBS/TTF nearing completion 


\begin{tabular}{|c|c|c|c|}
\hline $\begin{array}{c}\text { U.3. OEPT. OF COMM. } \\
\text { BIBLIOGRAPHIC DATA } \\
\text { SHEET (See instructions) }\end{array}$ & $\begin{array}{l}\text { 1. PUBLICATION OR } \\
\text { REPORT NO. } \\
\text { NBSIR } 84-2879\end{array}$ & Performing Organ. Report Nof & Publication Date \\
\hline 4. TITLE AND SUBTITLE & May 1984 \\
\hline
\end{tabular}

The NBS Tri-Directional Test Facility

5. AUTHOR(S)

Kyle Woodward and Frank Rankin

6. PERFORMING ORGANIZATION (If joint or other than NBS, see instructions)

7. Contract Grant No.

NATIONAL BUREAU OF STANDARDS

DEPARTMENT OF COMMERCE

WASHINGTON, D.C. 20234

9. SPONSORING ORGANIZATION NAME AND COMPLETE ADDRESS (Street, City, State, ZIP)

same as 6 above

10. SUPPLEMENTARY NOTES

Document describes a computer program; SF-185, FIPS Software Summary, is attached.

11. ABSTRACT (A 200-word or less foctual summary of most significant informotion. If document includes a significont bibliogrophy or literoture survey, mention it here)

A general description of a unique structural testing apparatus is presented. The apparatus is called the NBS Tri-directional Test Facility (NBS/TTF). The NBS/TTF can subject large structural elements to a wide variety of three-dimensional loadings including both translations and rotations in three orthogonal directions. The facility is computer based with all aspects of data acquisition, reduction, and display coordinated and controlled by a minicomputer. The minicomputer also controls the loading of test specimens as directed by the operator. The loads are applied by a closed-loop hydraulic system having seven independently servo-controlled hydraulic actuators. Test specimens having dimensions as large as $3 \mathrm{~m}$ long by $3 \mathrm{~m}$ deep by $3.5 \mathrm{~m}$ high may be installed and tested in the facility. Lateral forces of up to $\pm 900 \mathrm{kN}$ may be imposed on the test specimen in combination with vertical forces of up to \pm 1800 kiv.

12. KEY WOROS (Six to twelve entries; alphobetical order; capitalize only proper names; and separate key words by semicolons) Actuators; computer based; hydraulic; seismic; servo-controlled; structural testing; test facility; three dimensional.

13. AVAILABILITY

区ẌUnlimited

Z For Official Distribution. Do Not Release to NTIS

$\square$ Order From Superintendent of Documents, U.S. Government Printing Office, Washington. D.C. 20402.

XXOder From National Technical Information Service (NTIS), Springfield, VA. 22161

14. NO. OF

PRINTEO PAGES

4.4

15. Price

$\$ 8.50$ 


